Please do not remove this page

RMIT

UNIVERSITY

\title{
Machining with AICr-oxinitride PVD coated cutting tools
}

Pilkington, Antony; Dowey, Steve; Toton, Jimmy; Doyle, Edward

https://researchrepository.rmit.edu.au/esploro/outputs/9921859348901341/filesAndLinks?institution=61 RMIT_INST\&index=null

Pilkington, A., Dowey, S., Toton, J., \& Doyle, E. (2013). Machining with AICr-oxinitride PVD coated cutting tools. Tribology International, 65, 303-313. https://doi.org/10.1016/j.triboint.2013.03.020

Document Version: Accepted Manuscript

Published Version: https://doi.org/10.1016/j.triboint.2013.03.020

Repository homepage: https://researchrepository.rmit.edu.au

(C) 2013 Elsevier Ltd.

Downloaded On 2023/04/26 19:17:59 +1000

Please do not remove this page 
Thank you for downloading this document from the RMIT Research Repository.

The RMIT Research Repository is an open access database showcasing the research outputs of RMIT University researchers.

RMIT Research Repository: http://researchbank.rmit.edu.au/

\section{Citation:}

Pilkington, A, Dowey, S, Toton, J and Doyle, E 2013, 'Machining with AlCr-oxinitride PVD coated cutting tools', Tribology International, vol. 65, pp. 303-313.

See this record in the RMIT Research Repository at:

https://researchbank.rmit.edu.au/view/rmit:23357

Version: Accepted Manuscript

Copyright Statement: (c) 2013 Elsevier Ltd.

Link to Published Version:

http://dx.doi.org/10.1016/j.triboint.2013.03.020 


\section{Elsevier Editorial System(tm) for Tribology International Manuscript Draft}

Manuscript Number:

Title: Machining with AlCr-Oxinitride PVD Coated Cutting Tools

Article Type: Leeds-Lyon 2012

Keywords: Machining; PVD coating; abrasive adhesive wear; AlCr oxy-nitride

Corresponding Author: Mr. Antony Pilkington, B.Eng., MSc.

Corresponding Author's Institution: RMIT University

First Author: Antony Pilkington, B.Eng., MSc.

Order of Authors: Antony Pilkington, B.Eng., MSc.; S J Dowey, B. Eng, PhD; J T Toton, BSc; E D Doyle, BSc., MSc., PhD

Abstract: Physical Vapour Deposition (PVD) coating materials based on transition metal oxy-nitrides have been found to offer improved oxidation resistance for tooling applications. Arc deposited AlCrOxN1-x coatings were tested on M2 HSS drills in drilling 2.5D holes in AISI D2. At a speed of 30 $\mathrm{m} / \mathrm{min}$ and feed $0.025 \mathrm{~mm} / \mathrm{rev}$ the mean tool life was 17.2 holes / $\mu \mathrm{m}$ for coatings made with a N2/02 ratio of $0.9 / 0.1$. Coating deposition with a pulse bias of $10 \mathrm{kHz}$ was found to improve tool life in the drilling test by $10 \%$ compared to DC bias coatings. In milling of stainless steel AlCrOxN1-x coated carbide end mills cutting AISI 316 at $70 \mathrm{~m} / \mathrm{min}$ achieved a cut length $2.5 \mathrm{X}$ uncoated tools under the accelerated test conditions. 
A. Pilkington

Department of Applied Physics

RMIT University

14-7-5a Swanston Street

Melbourne

Victoria 3000

Australia

$11-9-2012$

To: The editor, Tribology International

Research article: Machining with AICr-Oxinitride PVD Coated Cutting Tools

\section{Dear Sir}

We have pleasure in submitting our paper to the Special Issue of the Proceedings of the $39^{\text {th }}$ Leeds-Lyon Tribology Symposium. A shorter version of the paper was presented by Antony Pilkington at the conference in Session X as Paper V.

We report the results of practical machining studies of recently developed $\mathrm{AlCr}$ oxinitride arc deposited PVD tool coatings. We present novelty in our coating design and manufacturing route which has not previously been reported in Tribology International. We have investigated the effects of oxygen incorporation and bias mode on the mechanical properties of AICrN PVD coatings.

Accelerated tool life testing was carried using round shank engineering tooling representing different levels of technological advancement. In drilling tests M2 HSS jobber drills represented a tool of baseline technology and an end milling study used an advanced design of vary-index carbide end-mill with robust life enhancing features such as edge finishing and sub-micron carbide specification. The AlCroxinitride coatings were shown to provide abrasive wear protection to HSS drills and the drill test was able to discriminate between the different treatments. We benchmarked the drill life by normalising against the coating thickness to benchmark against AICrN, the current state of the art PVD tool coating, in contrast to the more common and inappropriate use of TiN or uncoated HSS tooling. 
The measurement of tool wear was carried out using an Infinite Focus Microscope (Alicona IFM) and this was found to be advantageous. The novel use of this optical microscopy technique is certain to be of wider interest to Tribology International readers since it represents an important advancement in the quantification of surfaces, micro-geometry and wear. The practical advantages demonstrated by IFM imaging are in accuracy, non-destructive measurement and capability to measure features on complex geometries. This instrument has become indispensible in the author's laboratory for measurement of manufactured tool surfaces and wear resulting in service so we are pleased to showcase the capabilities in this paper.

Yours faithfully

Tony Pilkington

On behalf of the authors

A. Pilkington ${ }^{\star a b}$, S.J. Dowey ${ }^{a b c}$, J.T. Toton ${ }^{a b}$ and E.D. Doyle ${ }^{a b}$

a Department of Physics, School of Applied Sciences, RMIT University, Swanston Street, Melbourne, VIC 3000, Australia

${ }^{\mathrm{b}}$ Defence Materials Technology Centre, Level 2 No.24 Wakefield Street, Hawthorn, VIC 3122, Australia

' Sutton Tools Pty Ltd, 378 Settlement Road, Thomastown, VIC 3074, Australia

${ }^{*}$ Corresponding author: antony.pilkington@rmit.edu.au 
The research work submitted under the title "Machining with AICr-Oxinitride PVD Coated Cutting Tools"

Was conducted by the Defence Materials Research Centre ${ }^{b}$ and is the original work of the following authors:

A. Pilkington ${ }^{\star a b}$, S.J. Dowey ${ }^{a b c}$, J.T. Toton ${ }^{a b}$ and E.D. Doyle ${ }^{a b}$

a Department of Physics, School of Applied Sciences, RMIT University, Swanston Street, Melbourne, VIC 3000, Australia

${ }^{\mathrm{b}}$ Defence Materials Technology Centre, Level 2 No.24 Wakefield Street, Hawthorn, VIC 3122, Australia

c Sutton Tools Pty Ltd, 378 Settlement Road, Thomastown, VIC 3074, Australia ${ }^{*}$ Corresponding author: antony.pilkington@rmit.edu.au

The work is not submitted for publication elsewhere in this form and has not been published previously in any other journal.

Antony Pilkington

$11 / 9 / 2012$ 
- $A l C r \mathrm{C}_{x} \mathrm{~N}_{1-\mathrm{x}}$ coatings were deposited by cathodic arc with $\mathrm{DC}$ and pulse bias

- M2 HSS drills coated with AICrO $\mathrm{N}_{1-x}$ had reduced lip wear in drilling AISI D2

- $\mathrm{AlCrO}_{x} \mathrm{~N}_{1-x}$ coatings were more sensitive to $\mathrm{O}_{2}$ content than to bias mode

- Holes drilled per micron of coating thickness was used to compare coatings

- Coatings provided 2.5x wear life of uncoated end mills in machining AISI 316SS 


\title{
Machining with AICr-Oxinitride PVD Coated Cutting Tools
}

\author{
A. Pilkington ${ }^{\star a b}$, S.J. Dowey ${ }^{a b c}$, J.T. Toton ${ }^{\mathrm{ab}}$ and E.D. Doyle ${ }^{\mathrm{ab}}$ \\ a Department of Physics, School of Applied Sciences, RMIT University, Swanston \\ Street, Melbourne, VIC 3000, Australia \\ ${ }^{\mathrm{b}}$ Defence Materials Technology Centre, Level 2 No.24 Wakefield Street, Hawthorn, \\ VIC 3122, Australia \\ ${ }^{c}$ Sutton Tools Pty Ltd, 378 Settlement Road, Thomastown, VIC 3074, Australia \\ *Corresponding author: antony.pilkington@rmit.edu.au
}

keywords: tool wear, drilling, milling, PVD, oxi-nitride coating, cathodic arc, AICrN

\begin{abstract}
Physical Vapour Deposition (PVD) coating materials based on transition metal oxynitrides have been found to offer improved oxidation resistance for tooling applications. Arc deposited $A \mathrm{ACrO}_{x} \mathrm{~N}_{1-x}$ coatings were tested on M2 HSS drills by drilling 2.5D holes in AISI D2. At a speed of $30 \mathrm{~m} / \mathrm{min}$ and feed $0.025 \mathrm{~mm} / \mathrm{rev}$ the mean tool life was 17.2 holes $/ \mu \mathrm{m}$ for coatings made with a $\mathrm{N}_{2} / \mathrm{O}_{2}$ ratio of $0.9 / 0.1$. Coating deposition with a pulse bias of $10 \mathrm{kHz}$ was found to improve tool life in the drilling test by $10 \%$ compared to DC bias coatings. In milling of stainless steel AlCrO ${ }_{x} 1_{-x}$ coated carbide end mills cutting AISI 316 at $70 \mathrm{~m} / \mathrm{min}$ achieved a cut length 2.5X uncoated tools under the accelerated test conditions.
\end{abstract}

\section{Introduction}

The surface design of metal cutting tools for increased performance has presented tribologically challenging demands for the design of Physical Vapour Deposition (PVD) coatings. A combination of high temperature oxidation resistance, toughness and resistance to both chemical and abrasive wear processes is required [1,2] and conventional ceramic thin film coatings based on transition metal nitrides or carbides, 
such as $\mathrm{TiN}, \mathrm{CrN}$ or $\operatorname{TiCN}[3,4]$, have proved inadequate as cutting speeds are resistance with high hardness has been achieved by alloying of $\mathrm{Al}$ with $\mathrm{Ti}$ or $\mathrm{Cr}$ to provide TiAIN or CrAIN coatings with the capability to form a protective aluminium oxide in thermally activated tribocontacts [6]. The AICrN coatings with $\sim 70$ at $\%$ have been found to provide oxidation resistance to higher temperatures of $\sim 900{ }^{\circ} \mathrm{C}$ than the AlTiN coatings with similar Al content $[7,8]$ and the appearance of AIN (hexagonal) in the phase composition is delayed until higher temperatures.

These ternary nitride coatings provided tougher fine grained coating layers through a nanocomposite structure or nano-layered architectures $[9,10]$. Both TiAIN and AICrN have been successfully deposited and commercialised through sputtering [11], cathodic arc [12,13] and evaporation [14] PVD technologies. The hot hardness and diffusion barrier layer properties of $\mathrm{Al}_{2} \mathrm{O}_{3}$ [15-17] are attractive for tooling applications. However many technological and thermodynamic obstacles exist for the PVD of alumina coatings, with meta-stable phases presenting potential weaknesses through transformation in metal cutting applications [18-20]. In contrast alumina deposited by Chemical Vapour Deposition (CVD) has been extensively developed but remains unsuitable for the coating of engineering tooling manufactured from high speed steels (HSS) due to the process temperature of $\sim 900$ $1000^{\circ} \mathrm{C}[21]$ [22] [23]. Therefore other routes to improving the oxidation resistance of TiAIN and AICrN have been investigated e.g. by intentionally doping AICrN ceramic coatings with various elements, such as $\mathrm{Si}$ [24], including $\mathrm{Al}_{2} \mathrm{O}_{3}$ as a minority phase in a quaternary composition by $\mathrm{O}_{2}$ addition [25] or by including thin intermediate diffusion barrier layers of $\mathrm{TiN}$ [26] or $\mathrm{Al}_{2} \mathrm{O}_{3}$ in a multilayer coating [27]. The properties of sputtered AICr-O-N coatings have been shown to be dependent on both the $\mathrm{Al}-\mathrm{Cr}$ 
ratio and proportion of $\mathrm{O}_{2}$ incorporated $[24,28,29]$. Three types of sputtered $\mathrm{AlCr}$ oxinitride have been identified; at high $\mathrm{N}_{2}$ compositions $>78 \%$ the $\mathrm{FCC} \mathrm{CrN}$ structure is retained and the coatings have high hardness. Oxygen rich compositions exhibit a corundum type structure with medium-high hardness. Intermediate phase compositions had lower hardness which may include some amorphous material [16]. Barthelmä [30] showed that a series of arc deposited $\mathrm{AlCr}_{x} \mathrm{O}_{y} \mathrm{~N}_{z}$ coatings had a microhardness maxima of $55 \mathrm{GPa}$ for $10 \mathrm{At} \% \mathrm{O}_{2}$ content which was higher than comparative AICrN coatings (20 GPa). Najafi [31] prepared a series of $\operatorname{AICr}\left(\mathrm{O}_{x} \mathrm{~N}_{1-\mathrm{x}}\right)$ coatings at $550{ }^{\circ} \mathrm{C}$ using medium frequency pulse bias $(-35 \mathrm{~V})$ and $\mathrm{AlCr}$ cathodes in a Lateral Rotating Arc process with various $\mathrm{O}_{2} / \mathrm{N}_{2}$ ratios. Low $\mathrm{O}_{2}$ content coatings $(x<0.6)$ had high hardness $\sim 30-33 \mathrm{GPa}$ and fcc structure, coatings made with intermediate $\mathrm{O}_{2}$ content $(0.6<x<0.97)$ had lower hardness of $26 \mathrm{GPa}$ and coatings with $x>0.97$ had a phase composition of $\alpha-(\mathrm{Al}, \mathrm{Cr})_{2} \mathrm{O}_{3}$ with increased hardness of 28 GPa. The AlCr-oxinitrides with intermediate $\mathrm{O}_{2}$ content were metastable and on heating to $1000 \mathrm{C}$ in $\mathrm{Ar}$ transformed to a mixed phase composition of $(\mathrm{Al}, \mathrm{Cr})_{2} \mathrm{O}_{3}$ (in corundum structure) and fcc AlCrN.

In this work $\mathrm{N}_{2}$ rich $\mathrm{AlCrO}_{x} \mathrm{~N}_{1-x}$ arc deposited coatings were prepared at $480-500{ }^{\circ} \mathrm{C}$ with DC and pulse unipolar bias. Machining studies were carried out to investigate the wear protection properties of coatings in a drilling test machining AISI D2 with HSS drills and in milling of AISI 316 stainless steel with carbide end mills. A comparison with commercial $\mathrm{AlCrN}$ arc deposited coatings was made and the suitability of AICrN as an interface layer to prevent oxidation of the HSS during processing was assessed.

\section{Experimental}


A series of $\mathrm{AlCrO}_{x} \mathrm{~N}_{1-x}$ coatings were deposited in an industrial capacity cathodic arc PVD system (Balzers Innova) according to a two factor two level experimental design. The factors investigated were the reactive gas $\mathrm{N}_{2} / \mathrm{O}_{2}$ ratio with 2 levels of $0.9 / 0.1$ and $0.75 / 0.25$, and the negative bias mode with the levels set to either DC $($ level +1$)$ or pulse unipolar with a frequency of $10 \mathrm{KHz}$ (level -1). The bias level was maintained at an average value of $-80 \mathrm{~V}$ for both bias modes. Substrates were preheated to $450{ }^{\circ} \mathrm{C}$ and cleaned in-situ by Ar ion etching at $2 \times 10^{-2}$ mbar for 30 minutes prior to coating deposition. The coating temperature was maintained at 480 $500{ }^{\circ} \mathrm{C}$ which permitted the coating of both HSS and WC substrates in the same batch. The reactive gas pressure was maintained constant at $2.5 \times 10^{-2}$ mbar. The cathodes (targets) used had an Al:Cr composition of $70: 30$ at $\%$ and purity $99.95 \%$. The evaporators were operated with DC current in steered arc mode in order to maintain low macroparticle emission, which is well known to affect both the surface texture and morphology of cathodic arc PVD coatings [32-36]. The coating architecture adopted consisted of 3 layers, an AICrN bonding and functional layer of 1.5-2 $\mu \mathrm{m}$ thickness, a $100 \mathrm{~nm}$ transition layer with a linear variation of non-metal content from nitride to oxinitride with a composition controlled by the reactive gas volumetric flow rates. The toplayer of $A \mid \mathrm{CrO}_{x} \mathrm{~N}_{1-x}$ was then deposited to achieve an overall thickness in the range of 4-4.5 $\mu \mathrm{m}$. The deposition parameters are summarised in Table 1.

The series of $4 \mathrm{AlCrO}_{x} \mathrm{~N}_{1-\mathrm{x}}$ coatings were deposited onto polished $6 \times 1 \mathrm{~mm}$ thick WC-10 wt\% Co blades for characterisation studies. A Hysitron Ti950 Triboindentor equipped with a Berkovich indenter tip was used to measure the surface hardness and reduced modulus of the coatings. Indents were made on a $7 \times 7$ grid with $20 \mu \mathrm{m}$ spacing under a series of loads from 1-3 mN. Analysis of the force-indentation depth 
data was carried out with TriboScan v.9 software according to the methodology reported in ref. [37] incorporating the area function of the indenter tip.

Two types of engineering tooling were coated with $\mathrm{AlCrO}_{x} \mathrm{~N}_{1-x}$ for wear and performance evaluation in drilling and end milling. Commercial quality $6.35 \mathrm{~mm}$ (0.25") diameter AISI M2 HSS jobber drills were used for drilling trials. The drills were prepared by walnut shell blasting to remove edge burrs followed by a drag polishing process in abrasive media to radius the cutting edges and remove surface grinding damage. Fig. 1 shows the lip condition of a typical drill after this procedure. Edge burrs have been removed but the tool geometry and grinding surface texture were not significantly affected. Sets of 9 drills per coating group were randomly selected to enable statistical analysis of test results. A $50 \mathrm{~mm}$ thick $12 \% \mathrm{Cr} 1.5 \%$ C cold work tool steel plate (Cryodur 2379 [38] composition equivalent to AISI D2) in the annealed condition was used as the workpiece. The plate was prepared by face milling to $1 \mathrm{~mm}$ depth to remove the heat treatment scale from the surface. The workpiece hardness and adhesive properties greatly affect the tribological couple of drill cutting edge and chip contact, therefore the plate surface hardness and uniformity was investigated prior to the drill test with a Leeb D TIME GROUP TH107 rebound portable hardness tester. The surface hardness survey returned an average hardness of 515.1 HLD (approximately $235 \mathrm{HB}$ ) with a Std. Dev. of 15.2 HLD. Appropriate cutting conditions for the experimental test were established by drilling the plate with commercial AICrN coated test drills at various speeds in the range of $30-40 \mathrm{~m} / \mathrm{min}$. Cutting parameters of $30 \mathrm{~m} / \mathrm{min}$ and a feed of $0.125 \mathrm{~mm} / \mathrm{rev}$ achieved a mean drill life of $40-50$ holes with this set of test drills. These parameters were adopted for the testing of the $A \mathrm{ICrO}_{x} \mathrm{~N}_{1-x}$ coated drills. Blind holes were drilled in a randomised array to a depth of 2.5 diameters $(15.87 \mathrm{~mm})$ on a HAAS VF2 CNC 
machining centre with a flood coolant emulsion (Hocut 960) at a concentration of 78\%. The parameters represented an accelerated life test with failure criteria determined by an audible screech. A group of the prepared test drills were commercially coated with AICrN by a cathodic arc process and included in the study for comparison as a state of the art high performance PVD coating.

An accelerated performance study of coated carbide tooling was carried out by end milling of AISI 316L austenitic stainless steel in a HAAS VF Super 2 CNC machining centre. Carbide end mills of type E535-4mm Harmony vary-helix R35/38 were selected [39]. This tool had design features appropriate to high performance applications including edge preparation, increased corner strength provided by a $45^{\circ}$ chamfer and chatter resistance due to the vary helix. High edge toughness was provided by the sub-micron alloy carbide grade. The end mills were used in 3 surface conditions: uncoated (UC), coated with the 4 different $\mathrm{AlCrO}_{x} \mathrm{~N}_{1-x}$ coatings and a further set were coated with a commercial AICrN coating similar to that used in the drill tests. Climb milling was carried out with a radial depth of cut ae=0.3D (1.2 $\mathrm{mm})$, axial depth of cut $\mathrm{ap}=1 \mathrm{D}(4 \mathrm{~mm})$, speed $\mathrm{V}=70 \mathrm{~m} / \mathrm{min}$ and a feed per tooth of $\mathrm{fz}=0.022 \mathrm{~mm}$. The stainless steel workpiece in the form of a $50 \mathrm{~mm}$ square bar was supplied in the annealed condition. The mill finish was faced off from all surfaces prior to testing and the surface hardness was 267 HV30 with a Std. Dev. of 3 HV30. Minimum quantity lubrication (MQL) was used with a mist of Unist Coolube 2210. This was introduced into the cut by a compressed air stream at a dose rate of approximately $0.086 \mathrm{ml} / \mathrm{m}$ of cut length. Cutting force data for Fx, Fy and Fz was collected during machining of shorter $50 \mathrm{~mm}$ sections of the workpiece mounted on a Kistler 9257B 3 component dynamometer table. The dynamometer signals were input to Kistler 5011 charge amplifiers and converted to voltage signals, which were 
then routed through a Daqbook 200A multichannel analogue to digital converter with the sampling frequency set to $500 \mathrm{~Hz}$. The digital data was acquired and analysed using DaqView v7-13-14 software.

An Alicona Infinite Focus Microscope (IFM) was used to observe the wear progression of both drills and end mills. One drill from each coating run was imaged after drilling groups of 10 holes until failure. The corner wear $\mathrm{Vb}$ of the end mills was measured from IFM images using the Alicona IFM 3.5 software tools after each $12 \mathrm{~m}$ cut. The coating thickness on the drill and end mill lands was measured from SEM images made on polished transverse cross sections prepared from unworn sections of tools after completion of the machining tests.

\section{Results and discussion}

\subsection{Coating thickness, morphology and mechanical properties}

The coating thickness measurements in Table 1 indicated that the $A I C r O x N_{1-x}$ coatings had a thickness in the range of $4.4-4.78 \mu \mathrm{m}$ on drills and slightly greater thickness of $4.78-5.29 \mu \mathrm{m}$ on the end mills. The difference in coating thickness between end mills and drills may be attributed to differences in the jig masking during coating deposition. The $\mathrm{AlCrO}_{x} \mathrm{~N}_{1-x}$ coated drill groups had similar coating thickness; however the commercially coated tools had lower coating thicknesses of 2 $\mu \mathrm{m}$ on the drill lands and $2.6 \mu \mathrm{m}$ on the end mills.

Fig. 2 shows SEM images of fracture cross sections of the $A \mid C r O_{x} N_{1-x}$ coatings on WC. A feature of the cross sections was that the AICrN base layer had excellent adhesion to the WC substrate and all coatings had a compact morphology without evidence of columnar growth. No delamination was evident at the interface between the $\mathrm{AlCrN}$ and $\mathrm{AlCrO} \mathrm{N}_{1-x}$ layers in the coatings examined. This confirmed that the transition layer provided effective bonding as the ceramic film composition was 
varied from nitride to oxi-nitride. A difference in the topography of the fracture surface was observed between the DC coatings shown in Figs. 2(a) (c) and pulse bias coatings shown in Figs. 2(b) (d). The DC bias coatings exhibited a more granular or faceted fracture, similar to that evident in the AICrN base layers, whereas the pulse bias coatings of Run 3 and Run 4 featured a smoother fracture cross section. The addition of $\mathrm{O}_{2}$ during the deposition of the $\mathrm{AlCrO}_{x} \mathrm{~N}_{1-x}$ toplayer had an adverse effect on the surface roughness in comparison to the commercial AlCrN coatings. The $\mathrm{AlCrO}_{x} \mathrm{~N}_{1-\mathrm{x}}$ coatings featured a greater number of larger $\sim 2-10 \mu \mathrm{m}$ diameter surface macroparticles. It was evident that the macroparticles introduced morphological defects into the $\mathrm{AlCrO}_{x} \mathrm{~N}_{1-x}$ coating layers with an indication from surveys of larger areas of the SEM images that the macroparticle incorporation gradually increased after the transition layer was formed. This was indicative of a gradual poisoning effect of $\mathrm{O}_{2}$ on the AICr target surface with the growth of oxide nodules. Fig. 3 shows an example of the appearance of an $\mathrm{O}_{2}$ poisoned target face after run 3. Investigation of non-conductive oxide nodules on a cathode by IFM indicated step heights of $500-800 \mathrm{~nm}$ and characteristic diameters of $0.5-1 \mathrm{~mm}$. It is therefore probable that these nodules acted as both physical and dielectric barriers for the movement of arc spots and may hinder arc splitting. The effect on macroparticle emission is opposite to the type 1 (contaminated surface) arc discharges operating in $\mathrm{Ar}+\mathrm{O}_{2}$ described in [40] which reported greater arc spot speed for cathodic arcs operated with $\mathrm{O}_{2}$. Both increased current density and reduced arc spot mobility are well known to promote the appearance of larger diameter macroparticles in the arc evaporated material flux [3, 41] and additions of $\mathrm{Si}$ to the $\mathrm{AICr}$ cathode composition have been proposed recently to address this issue or through the use of pulsed arc current by Ramm [42]. 
The surface texture of the $A I C r O x N_{1-x}$ coatings caused some difficulties for the nanoindentation investigation and it was necessary to polish the sample surface using $3 \mu \mathrm{m}$ diamond compound in order to achieve reliable nanoindentation results. Table 2 shows data of the coating hardness and reduced modulus which is plotted in Fig. 4 where it is clear that the series of coatings formed 2 groups based on the $\mathrm{H}$ and $E^{\prime}$ values. Coatings from runs 1 and 3 made using a $\mathrm{N}_{2} / \mathrm{O}_{2}$ ratio of $0.75 / 0.25$ had lower $\mathrm{H}$ values in the range of 24.6 -24.8 GPa. The coatings made using lower $\mathrm{O}_{2}$ contents $\left(\mathrm{N}_{2} / \mathrm{O}_{2}\right.$ ratio $\left.0.9 / 0.1\right)$ had a higher hardness of $32 \mathrm{GPa}$. which was comparable to the commercial AICrN coating.

Fig. 5(a) shows the interaction plot of the hardness values for the $\mathrm{AlCrO}_{x} \mathrm{~N}_{1-\mathrm{x}}$ groups. No dependence on the bias mode is evident at the lower $\mathrm{O}_{2}$ level whereas a small effect is shown at the higher $\mathrm{O}_{2}$ level of 0.25 . The effect of the $\mathrm{O}_{2}$ content on $\mathrm{H}$ is significant, shown in the lower left panel of Fig. 5(b). None of these coatings can be classed as "super hard" [43] and had a lower hardness than the 44 -55 GPa reported in [30] for arc deposited AICrON coatings. The reduced modulus E' values showed a more complex relationship than for the hardness. The commercial AICrN coating had the largest value of $\mathrm{E}^{\prime}$ of $382.8 \mathrm{GPa}$. The lower $\mathrm{O}_{2}$ content coatings had intermediate values of $332-337 \mathrm{GPa}$ whereas the high $\mathrm{O}_{2}$ content coatings had the lowest $\mathrm{E}^{\prime}$ values of 262-285 GPa. in Fig. 5(b) there is a small dependency of $\mathrm{E}^{\prime}$ on bias mode since both pulse bias coatings had greater $E^{\prime}$ than the DC values for the two different $\mathrm{O}_{2}$ contents. However some caution in interpretation is necessary due to the difficulties inherent in obtaining reliable indents from arc deposited coatings, indicated by the standard deviation in the $\mathrm{E}^{\prime}$ value (in Table 2) for the Run 3 coating. The toughness of PVD coatings may be characterised by the H/E relationship [44] which is a measure of the elastic deformation capacity of a coating and is important 
in metalworking where the tool is subject to cyclic impact loading. The H/E ratios calculated from the experimental values of $\mathrm{H}$ and $\mathrm{E}^{\prime}$ of the $\mathrm{AlCrO}_{x} \mathrm{~N}_{1-x}$ coatings fall in a range of 0.087 to 0.98 which indicated that these coatings may be expected to show similar toughness to the commercial AICrN coating.

\subsection{Drilling of D2 Tool Steel Plate}

The number of holes drilled to failure by the coating groups is presented as a boxplot in Fig. 6(a). The plot indicates the data range, median number of drilled holes and the $25 \%$ and $75 \%$ quartile positions. The average number of holes drilled ranged from 36 to 80 across the drill groups. The median values for the $A \mid C r O x N_{1-x}$ coatings showed a trend of increasing number of holes with decreasing $\mathrm{O}_{2}$ content in the range 0.25 to 0.1 . Comparing the data groups by bias level it is clear that the pulse bias increased the average drill life in comparison to the DC case for both the higher $\mathrm{O}_{2}$ level (runs 1 and 3 ) and also for the lower $\mathrm{O}_{2}$ level. However the data groups overlap for the coatings made with a $\mathrm{N}_{2} / \mathrm{O}_{2}$ ratio of $0.9 / 0.1$ and the difference in tool life is therefore not statistically significant. The group of drills coated with $2 \mu \mathrm{m}$ of AlCrN showed the lowest median number of holes drilled and also the lowest variance. It is well known that coating thickness has a significant effect on the drill life therefore the data was normalised according to the average coating thickness for each group (Fig. 6(b)). The AICrN coated drills showed the highest mean number of holes per $\mu \mathrm{m}$ at 17.8. The pulse bias $\mathrm{AlCrO}_{x} \mathrm{~N}_{1-\mathrm{x}}$ coating with a $\mathrm{N}_{2} / \mathrm{O}_{2}$ ratio of $0.9 / 0.1$ had wear resistant properties similar to the commercial AICrN coating with 17.2 holes per $\mu \mathrm{m}$ under these test conditions. Fig. 6 (c) shows that both $\mathrm{O}_{2}$ level and bias level have an effect on the number of holes drilled per micron. The effect of bias is greater at the higher $\mathrm{O}_{2}$ level and the effect of $\mathrm{O} 2$ level is greater for the DC bias coatings. 
The lip wear for an AICrN coated drill after 30 holes is shown in the IFM image in Fig. 7(a). This group had the lowest average number of holes drilled. A $20 \mu \mathrm{m}$ wide wear land can be seen linking the worn corner to the chisel point. The negative rake of the chisel to the drill centre has been completely worn away so that the chisel point behaves as a semi-conical indenter. The rake face at the outer corner shows the formation of a wear land which together with the severe blunting of the chisel edge indicates imminent drill failure, which occurred at 36 holes for the drill imaged. Fig. 7(b) shows a drill from $\mathrm{R} 4\left(10 \mathrm{kHz} \mathrm{N} \mathrm{N}_{2} / \mathrm{O}_{2} 0.9 / 0.1\right)$ which exhibited lower wear than the AICrN coated drill. The lip wear again appeared uniform and the wear process is mainly abrasive wear since the wear land did not show oxidation discolouration and workpiece adhesion was minimal. This drill showed the appearance of an outer wear facet on the rake face after 60 holes, evident in Fig. 7 (c) but continued to drill a total of 80 holes. The thicker PVD coating on the $\mathrm{AlCrO}_{x} \mathrm{~N}_{1-x}$ drills from Run 4 together with the high hardness of $32 \mathrm{GPa}$ provided abrasive wear resistance against the hard chromium carbides present in the workpiece [45] and a degree of thermal protection which enabled the greater number of holes to be drilled.

It was observed that the average performance of the various treatments in holes/ $\mu \mathrm{m}$ closely followed the trend in hardness values (Table 2) and also $E$, as the $H / E$ ratio was nominally similar.

\subsection{End milling of austenitic stainless steel AISI 316L}

The progression of corner wear $\mathrm{Vb}$ with cut length is shown in Fig. 8. The cut length achieved by the uncoated end mill was $6.9 \mathrm{~m}$ whereas the coated tools all cut more than $24 \mathrm{~m}$. The general trend of the corner wear showed a high initial rate (wear-in phase) which then stabilised at a lower rate (steady state wear) after $5 \mathrm{~m}$. The test data did not include a wear out phase, except for the AICrN coated tool. The 
accelerated conditions eventually caused tool failure by shank fracture at the flute run out rather than by edge wear or chipping of the margins. Lubrication of the cutting process by the MQL oil mist was adequate and no thermally decomposed oil residue was apparent on the end mills. The greatest wear rate $\mathrm{Vb}$ was shown by the uncoated end mill and the wear of $A \mathrm{CrO}_{x} \mathrm{~N}_{1-x}$ coatings from runs 3-4-5 showed a similar $\mathrm{Vb}$ at $5 \mathrm{~m}$ cut length. However, the commercial AICrN coating and the AICrO $\mathrm{N}_{1-x}$ coating from run 1 showed lower values of $\mathrm{Vb}$ for the $\mathrm{DC} \mathrm{N}_{2} / \mathrm{O}_{2}$ ratio 0.75 / 0.25 coating from run 1 . A discussion of the milling results in terms of the measured mechanical properties of the coatings is more complex than for the drilling test. The end mills coated in run 1 and run 3 with the same $\mathrm{N}_{2} / \mathrm{O}_{2}$ ratio of $0.75 / 0.25$ have similar hardness values of 24-25 GPa and similar thickness values of 4.4-4.8 $\mu \mathrm{m}$ but showed an opposite response of $\mathrm{Vb}$ with cut length, representing the lowest and highest values from the $A \mathrm{ICrO}_{x} \mathrm{~N}_{1-x}$ coated tooling respectively. This outcome is opposite to the performance of the run 1 coatings in the drilling test where the coatings from run 1 produced the lowest number of holes per micron. The performance of the run 1 coating in this end milling test merits further investigation. In milling the lower $E^{\prime}$ value measured for this coating may have provided an advantage under the repetitive impact loadings applied to the end mill tooth as the cut commences.

Plots of cutting forces against data point for uncoated (UC) and coated tools are presented in Figs. 9(a)-(f) respectively. The force Fx in the direction of table feed showed peaks typical of climb milling at the entry and exit of the cut. The magnitude of the Fy forces (normal reaction force) was approximately $3 x$ greater than the Fx values. The uncoated tool and coated tools showed a different response in cutting forces as wear of the corner and margins increased. Fig. 10 shows the change in 
average Fy for the end mills after $5 \mathrm{~m}$ cut length (UC) and $24 \mathrm{~m}$ (coated tools). The average forces of the uncoated tool were initially $143-155 \mathrm{~N}$ but increased by $49 \%$ to $215 \mathrm{~N}$ after a cut length of $5 \mathrm{~m}$. In Fig 9(a) the peaks in Fy are $250 \mathrm{~N}$ for the worn tool, which was attributed to the $100 \mu \mathrm{m}$ margin creating a larger impact force on entering the workpiece. The coatings made at an $\mathrm{N}_{2} / \mathrm{O}_{2}$ ratio of $0.75 / 0.25$ showed a lower average Fy than coatings made at $0.9 / 0.25$, which may indicate lower adhesive forces between chip and rake face. The AICrN coating had an initial Fy of $143 \mathrm{~N}$ which was intermediate between runs 1 and 3 (higher $\mathrm{O}_{2}$ coatings) and that of runs 4 and 5 . Run 1 showed no change in the average Fy and this is consistent with the low corner wear shown in Fig. 8. The Fy values in fig. 10 can be partly explained by the edge radii measured on the unused tools. Fig. 11 shows that the UC, AICrN and lower $\mathrm{O}_{2}$ coatings had a linear relationship for $\mathrm{Fy}$ with edge radius and these coated tools show an edge radius approximately equal to the uncoated tool plus the AICrN or $\mathrm{AlCrO}_{x} \mathrm{~N}_{1-x}$ coating thickness. The $\mathrm{AlCrO}_{x} \mathrm{~N}_{1-x}$ coatings made with higher $\mathrm{O}_{2}$ ratio do not follow the radius-Fy relationship and this suggests that the lower Fy is due to tribological properties and the $\mathrm{DC} 0.75 \mathrm{~N}_{2} 0.25 \mathrm{O}_{2}$ may behave as a solid lubricant in this particular workpiece-coating-MQL system.

IFM images of the end mill margins are shown in Fig. 12. In Fig. 12(a) the UC tool is seen to have the lowest initial edge radius and was therefore the sharpest tool but had greater flank wear (Fig. 12(b)) and corner recession. The AICrN coated tool had low wear of both rake and flank and in Fig. 12(d) the hard coating can be seen as a step close to the margin. The $\mathrm{DC} 0.75 \mathrm{~N}_{2} 0.25 \mathrm{O}_{2}$ coating showed wear of the AICrO $\mathrm{N}_{1-x}$ layer from an early stage yet still had an adherent $\mathrm{AICrN}$ base layer and the lowest exposed carbide of the tools after $24 \mathrm{~m}$ cut length, Fig. 12(e). The coatings in Figs. $12(f)$ to $(\mathrm{h})$ showed wear of the $\mathrm{AlCrO}_{x} \mathrm{~N}_{1-\mathrm{x}}$ layer on the flank intermediate 
between run 1 and the AICrN tool. of the Adhesion of the AISI 316 was evident only on the edges of the DC $0.9 \mathrm{~N} 20.1 \mathrm{O}_{2}$ tool in Fig. 12(g).

Austenitic stainless steel is well known to promote adhesive wear and subject the tool cutting edges to high stress due to work hardening from prior cuts together together with high temperatures in zone 2 of the secondary shear zone [46-48]. The wear mechanism of the UC tool was examined in detail in an SEM (Fig. 13(a)) where the eccentric diametrical relief is at the left of the image and the rake face is on the right. A wear land of $100 \mu \mathrm{m}$ had developed with an adherent build up at the cutting edge junction with the rake face and this material provided some protection for the tool carbide material. The transient nature of this lamellar build up was indicated by the detachment of a ribbon which showed a conformal boundary with the remaining adherent layer. A detail of the cutting edge is shown in Fig. 13(b) where the chip flow direction was from centre to bottom right down the rake face. The wear mechanism of the uncoated tool is indicated by the evidence of adherent workpiece material on the upper flanks of the grinding grooves and a step-like loss of carbide tool material by micro fracture along some of the crests. The submicron grain size of the alloy carbide was therefore beneficial in achieving a low wear rate since no edge breakdown (notching) was observed and fracture was limited to a depth of the nominal grain size. An SEM image of the AICrN coated endmill is shown after $31 \mathrm{~m}$ of cutting in Fig. 13(c). The worn cutting edge is different to that of the uncoated tool and has retained a smooth radius with only $\sim 10 \mu \mathrm{m}$ of carbide exposed. Adherent workpiece material is evident on the flank relief but is plate-like rather than continuous. The AICrN coating has been effective in preventing workpiece adhesion along the rake to a depth of $\mathrm{fz}$. In Fig. 13(d) wear of the AICrON coating from run 4 is 
evident as a step on the rake face, however the area of worn carbide exposed is still low despite the extent of the coating flank wear of $80-100 \mu \mathrm{m}$.

\section{Conclusions}

AICrO $\mathrm{N}_{1-x}$ coatings deposited with an $\mathrm{N}_{2} / \mathrm{O}_{2}$ ratio of $0.9 / 0.1$ had hardness values of $32 \mathrm{GPa}$ and were harder than coatings made with the $\mathrm{N} 2 / \mathrm{O} 2$ ratio of $0.75 / 0.25$ which had hardness values of $24 \mathrm{GPa}$. A $2 \mu \mathrm{m}$ adhesion layer of AICrN was found to be effective in preventing deterioration of the tool materials in the $\mathrm{O}_{2}$ plasma deposition process.

The average number of $2.5 \mathrm{D}$ blind holes drilled by $\mathrm{AlCrO}_{\mathrm{x}} \mathrm{N}_{1-\mathrm{x}}$ coated $\mathrm{M} 2$ jobber drills in D2 tool steel was found to be related to the coating hardness. The coatings deposited onto M2 HSS drills with a $\mathrm{N}_{2} / \mathrm{O}_{2}$ ratio of $0.9 / 0.1$ performed better than coatings made with the $0.75 / 0.25 \quad \mathrm{~N}_{2} / \mathrm{O}_{2}$ ratio. Pulse bias coatings had a longer lifetime than DC bias coatings for similar reactive gas deposition ratios. In the drilling test the performance of the pulse bias $0.75 / 0.25 \mathrm{~N}_{2} / \mathrm{O}_{2}$ coating was 17.2 holes per $\mu \mathrm{m}$ which was comparable to the commercial AICrN coatings with 17.8 holes per $\mu \mathrm{m}$. Carbide end mills coated with $\mathrm{AlCrO}_{x} \mathrm{~N}_{1-\mathrm{x}}$ showed lower edge and corner wear than uncoated tools in the machining of AISI 316 austenitic stainless steel and produced a cut length greater than $24 \mathrm{~m}$ in the accelerated cutting test. The milling test showed that the $\mathrm{AlCrO}_{x} \mathrm{~N}_{1-\mathrm{x}}$ coating made with $\mathrm{DC}$ bias at a $\mathrm{N}_{2} / \mathrm{O}_{2}$ ratio of $0.75 / 0.25$ showed the lowest corner wear in the milling test whereas this coating achieved the lowest performance when drilling AISI D2 tool steel.

\section{Acknowledgements}

This body of work was undertaken by the DMTC with researchers from RMIT University and Sutton Tools Pty. Ltd. The DMTC was established and is supported 
by the Australian Government's Defence Future Capability Technology Centre (DFCTC) initiative.

The industrial DMTC partner Sutton Tools Pty. Ltd. provided sponsorship, tooling, research materials, coating deposition and access to the $\mathrm{CNC}$ machining laboratory of the Advanced Surface Solutions Facility (ASSF). The technical assistance of J. Phung of Sutton Tools Pty. Ltd. in carrying out the machining experiments is gratefully acknowledged.

The authors acknowledge the facilities, and the scientific and technical assistance, of the Australian Microscopy \& Microanalysis Research Facility at the RMIT Microscopy \& Microanalysis Facility, at RMIT University. The authors express their thanks to A. Pagon of RMIT Applied Physics for providing assistance and expertise in carrying out the nanoindentation investigations.

1. Holleck, H., Materials selection for hard coatings. J. Vac. Sci. Technol. A, 1986. 4(6): p. 2661-2669.

2. Hogmark, S., Jacobson, S., Larsson, M., Design and evaluation of tribological coatings. Wear, 1999. 246: p. 20-33.

3. Boxman, R.L., Martin, P.J., ed. Vacuum Arc Science and Technology: Fundamentals and Applications. 1995, Noyes Publications: New Jersey.

4. Münz, W.-D., Titanium aluminum nitride films: $A$ new alternative to TiN coatings. J. Vac. Sci. Technol. A, 1986. 4(6): p. 2717-2726.

5. Fox-Rabinovich, G.S., Kovalev A.I., Aguirre M.H., Beake B.D., Yamamoto, K., Veldhuis, S.C., Endrino, J.L., Wainstein, D.L., Rashkovskiy, A.Y., Design and performance of AlTiN and TiAICrN PVD coatings for machining of hard to cut materials. Surface \& Coatings Technology, 2009. 204: p. 489-496.

6. Kawate, M., Hashimoto, A. K., Suzuki, T., Oxidation resistance of $\mathrm{Cr}_{1-X} \mathrm{Al} \mathrm{I}_{X} \mathrm{~N}$ and $T i_{1-X} A I_{X} N$ films. Surface and Coatings Technology, 2003. 165: p. 163-167.

7. Willmann, H., Mayrhofer, P. H., Hultman, L., Mitterer, C., Hardness evolution of Al-Cr-N coatings under thermal load. J. Mater. Res., 2008. 23(11): p. 2880-2885.

8. Reiter, A.E., Derflinger, V.H., Hanselmann, B., Bachmann,T., Sartory, B., Investigation of the properties of $A l_{1-x} C r_{x} N$ coatings prepared by cathodic arc evaporation. Surface \& Coatings Technology, 2005. 200: p. 2114-2122.

9. Stueber, M., Holleck, H., Leiste, H., Seemann, K., Ulrich, S., Ziebert, C., Concepts for the design of advanced nanoscale PVD multilayer protective thin films. Journal of Alloys and Compounds, 2009. 483: p. 321-333. 
10. Yashar, P.C., Sproul, W.D., Nanometer scale multilayered hard coatings. Vacuum, 1999. 55: p. 179-190.

11. Erkens, G., Cremer, R., Hamoudi, T., Bouzakis, K.-D., Mirisidis, I., Hadjiyiannis, S., Skordaris, G., Asimakopoulos, A., Kombogiannis, S., Anastopoulos, Anastopoulos, J., Efstathiou, K., Properties and performance of high aluminum containing $(\mathrm{Ti}, \mathrm{Al}) \mathrm{N}$ based supernitride coatings in innovative cutting applications. Surface \& Coatings Technology, 2004. 177 -178 p. 727734.

12. Endrino, J.L., Fox-Rabinovich, G.S., Gey, C., Hard AlTiN, AlCrN PVD coatings for machining of austenitic stainless steel. Surface \& Coatings Technology, 2006. 200: p. 6840-6845.

13. Kalss, W., Reiter, A., Derflinger, V., Gey, C., Endrino, J.L., Modern coatings in high performance cutting applications. International Journal of Refractory Metals \& Hard Materials, 2006. 24: p. 399-404.

14. Wang, L., Nie, X., Housden, J., Spain, E., Jiang, J.C., Meleti. E.I., Leyland, A., Matthews, A., Material transfer phenomena and failure mechanisms of a nanostructured $\mathrm{Cr}-\mathrm{A}-\mathrm{N}$ coating in laboratory wear tests and an industrial punch tool application. Surface \& Coatings Technology, 2008. 203: p. 816821.

15. Ashenford, D.E., Long, F., Hagston, W. E., Lunn, B., Matthews, A. , Experimental and theoretical studies of the low-temperature growth of chromia and alumina. Surface \& Coatings Technology, 1999. 116-119: p. 699704.

16. J.M. Schneider, W.D.S., A. Matthews. , Phase formation and mechanical properties of alumina coatings prepared at substrate temperatures less than $500^{\circ} \mathrm{C}$ by ionized and conventional sputtering. . Surface \& Coatings Technology, 1997. 94-95: p. 179-183.

17. Musil, J., Bla`zek, J., Zemana, P., Prokšová, S`., S`ašek, M., C`erstv'y, R. , Thermal stability of alumina thin films containing $\gamma$-Al2O3 phase prepared by reactive magnetron sputtering. App. Surface Science, 2010. 257: p. 10581062.

18. Carter, D., McDonough, G., Enhanced reactively sputtered Al2O3 deposition by addition of activated reactive oxygen, in SVC 42nd Annual technical Conference. 1999 Society of Vacuum Coaters: Chicago, IL, USA. p. 1-8.

19. Andersson, J.M., Low-temperature growth of alumina, in Thin Film Physics Division, Department of Physics and Measurement Technology. 2004, Linköping University: SE-581 83 Linköping, Sweden. p. 70.

20. Dragoo, A.L., Diamond, J.J., Transitions in vapor deposited alumina from 300 to 1200 C. J. Am. Ceram. Soc., 1967. 50(11): p. 568-574.

21. Schintlmeister, W., Wallgram, W., Kanz, J., Properties, applications and manufacture of wear resistant hard material coatings for tools. Thin Solid Films, 1983. 107: p. 117-127.

22. Ruppi, S., Deposition, microstructure and properties of texture controlled CVD $\alpha-\mathrm{Al}_{2} \mathrm{O}_{3}$ coatings. Int. J. Refractory metals and Hard Materials., 2005. 23: $\mathrm{p}$. 306-316.

23. Laimer, J., Fink, M., Mitterer, C., Sto" ri, H., Plasma CVD of aluminaUnsolved problems. Vacuum, 2005. 80: p. 141-145.

24. Karimi, A., Morstein, M., Cselle, T., Infuence of oxygen content on structure and properties of multi-element AICrSiON oxynitride thin films. Surface \& Coatings Technology, 2010. 204: p. 2716-2722. 
25. Leyendecker, T., Rass, I., Erkens, G., Feldhege, M. , TiAIN- $\mathrm{II}_{2} \mathrm{O}_{3} P V D-$ multilayer for metal cutting operation. Surface and Coatings Technology, 1997. 97(1-3): p. 790-793.

26. Endrino, J.L., Fox-Rabinovich, G.S., Reiter, A., Veldhuis, S.V., Galindo, R.E., Oxidation tuning in AICrN coatings. Surface \& Coatings Technology, 2007. 201: p. 4505-4511.

27. Schier, V., Doerwald, D., Break thorugh in PVD coated aluminium oxide. Hauzer For You, 2005(10): p. 3-4.

28. Stueber, M., Diechle, D., Leiste, H., Ulrich, S., Synthesis of Al-Cr-O-N thin films in corundum and f.c.c. structure by reactive r.f. magnetron sputtering. Thin Solid Films 2011. 519: p. 4025-4031.

29. Stüber, M., Albers, U., Leiste, H., Seemann, K., Ziebert, C., Ulrich, S. , Magnetron sputtering of hard $\mathrm{Cr}-\mathrm{Al}-\mathrm{N}-\mathrm{O}$ thin films. Surface \& Coatings Technology, 2008. 203: p. 661-665.

30. Barthelmä, F., Frank, H., Mahr, P., Reich, S., Oxygen-improved hard coatings for high performance cutting processes. Procedia CIRP, 2012. 1: p. $208-213$.

31. Najafi, H., Karimi, A., Dessarzin, P., Morstein, M., Correlation between anionic substitution and structural properties in $A / C r\left(O_{x} N_{1-x}\right)$ coatings deposited by lateral rotating cathode arc PVD. Thin Solid Films, 2011. 520: p. 1597-1602.

32. Anders, A., Approaches to rid cathodic arc plasmas of macro and nanoparticles: a review. Surface \& Coatings Technology, 1999. 120-121: p. 319-330.

33. Ellrodt, M., \& Kühn, M., Investigations of the cathode spot dynamics in a vacuum arc coating process. Contributions to Plasma Physics, 1996. 36(6): p. 687-696.

34. B"uschel, M., Grimm, W., Influence of the pulsing of the current of a vacuum arc on rate and droplets. Surface \& Coatings Technology, 2001. 142-144: p. 665-668.

35. Ehiasarian, A.P., Hovsepian, P.Eh., New, R., Valter, J., Influence of steering magnetic field on the time resolved plasma chemistry in cathodic arc discharges. Journal of Physics D: Applied Physics, 2004. 37(15): p. 521-524.

36. Harris, S.G., Doyle, E.D., Wong, Y.-C., Munroe, P.R., Cairney, J.M., Long, J.M., Reducing the macroparticle content of cathodic arc evaporated TiN coatings. Surface \& Coatings Technology, 2004. 183: p. 283-294.

37. Pharr, G.M., Oliver, W.C., Measurement of thin film mechanical properties using nanoindentation. MRS Bulletin, 1992(July): p. 28-33.

38. Cryodur® 2379 Technical Data Sheet. 2012, Smolz + Bickenbach.

39. Sutton Tools Pty Ltd., http://www.sutton.com.au/assets/515/1/499980315_HighPerformance_Catalo gue_Aust_2011.pdf. 2011. p20.

40. Mustapha, N., Howson, R.P., Comparison of unbalanced magnetron sputtering and filtered arc evaporation for the preparation of films onto insulating substrates. Vacuum, 1998. 49(2): p. 75-79.

41. Münz, W.-D., Smith, I.J., Lewis, D.B., Creasey, S., Droplet formation on steel substrates during cathodic steered arc metal ion etching. Vacuum, 1997. 48(5): p. 473-481.

42. Ramm, J., Neels, A., Widrig, B., Döbeli, M., Vieira, L. d-A., Dommann, A., Rudigier, $\mathrm{H}$., Correlation between target surface and layer nucleation in the 
synthesis of Al-Cr-O coatings deposited by reactive cathodic arc evaporation. Surface \& Coatings Technology, 2010. 205: p. 1356-1361.

43. Musil, J., Hard and superhard nanocomposite coatings. Surface \& Coatings Technology, 2000. 125: p. 322-330.

44. Leyland, A., Matthews, A., On the significance of the H/E ratio in wear control: a nanocomposite coating approach to optimised tribological behaviour. Wear, 2000. 246: p. 1-11.

45. Sandberg, O., J"onson, L. . New generation of tool steels made by spray forming. in Proceedings of the 6th International Tooling Conference. 2002. Karlstad.

46. Liew, W.Y.H., Ding, X., Wear progression of carbide tool in low-speed end milling of stainless steel. Wear, 2008. 265: p. 155-166.

47. Abou-El-Hossein, K.A., Yahya, Z. , High-speed end-milling of AISI 304 stainless steels using new geometrically developed carbide inserts. Journal of Materials Processing Technology, 2005. 162-163: p. 596-602.

48. Doyle, E.D., Horne, J.G., Tabor, D., Frictional Interactions between chip and rake face in continuous chip formation Proc. R. Soc. Lond. A 1979. 366: p. 173-183. 


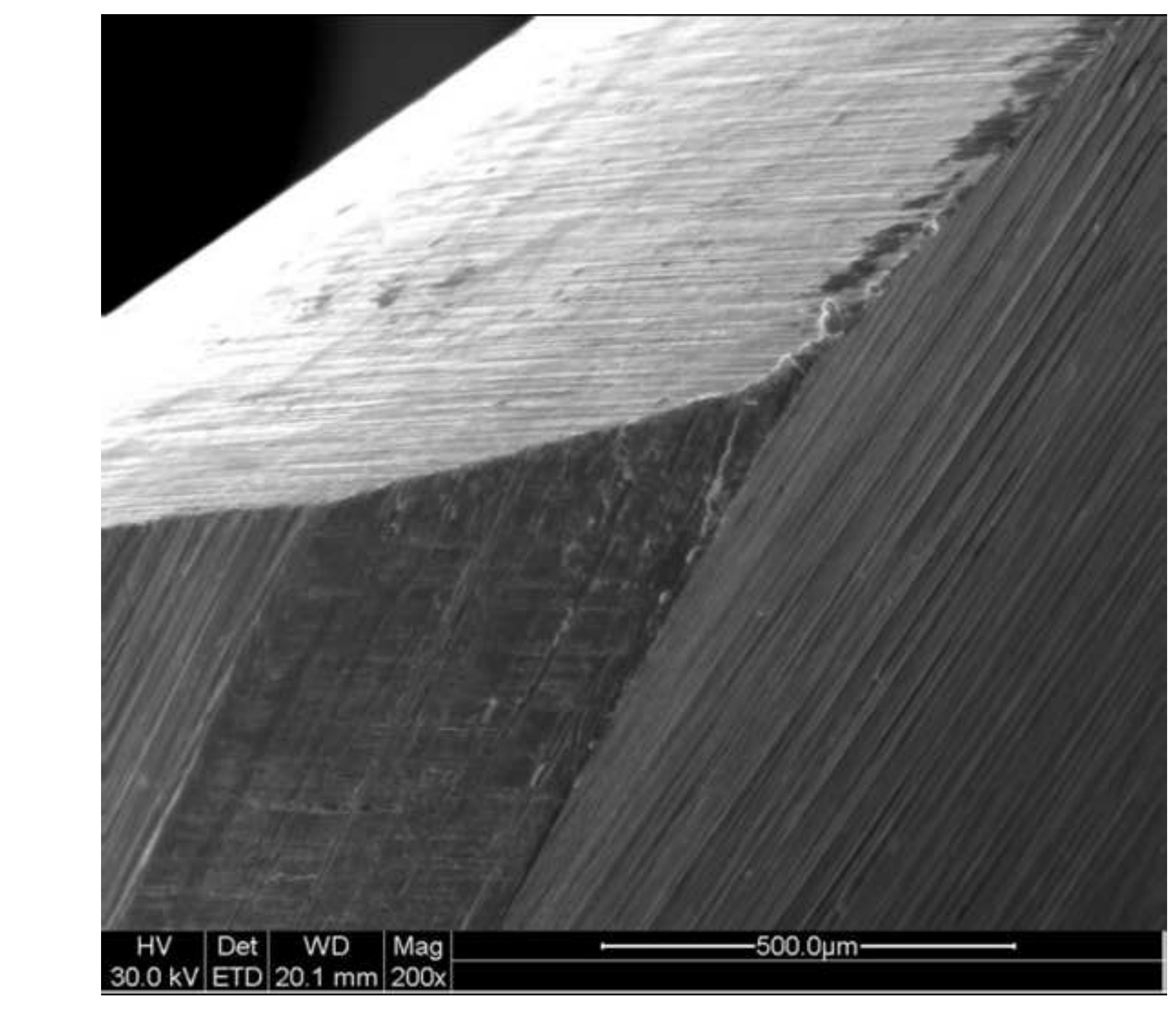

$30.0 \mathrm{kV}$ ETD $20.1 \mathrm{~mm} \mathrm{200x}$

Fig. 1. Uncoated 1/4" Dia. M2 HSS Jobber drill.
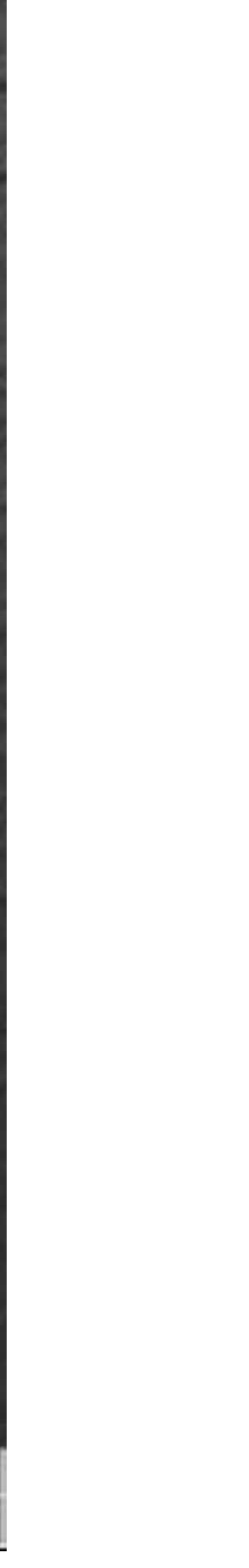


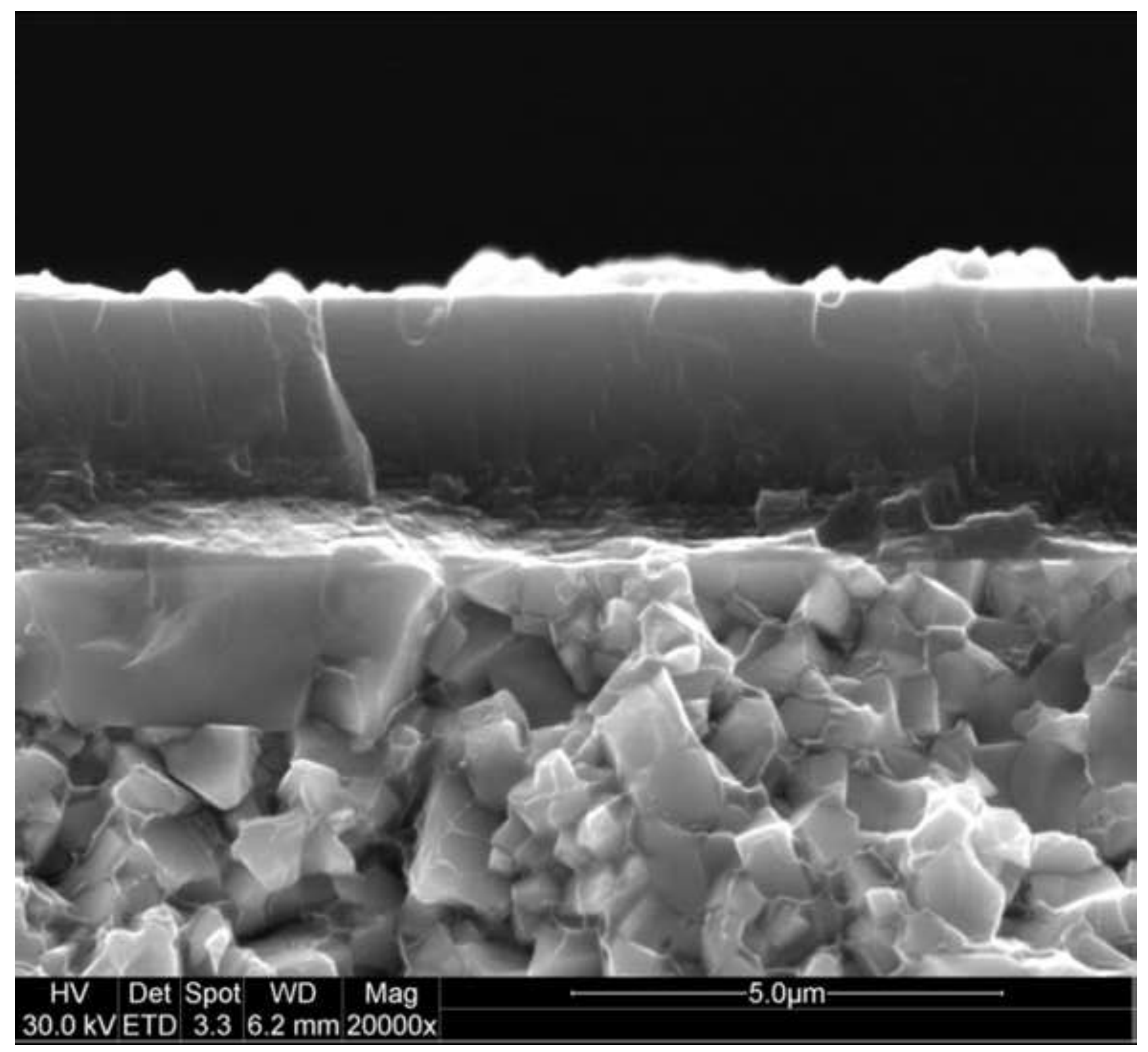




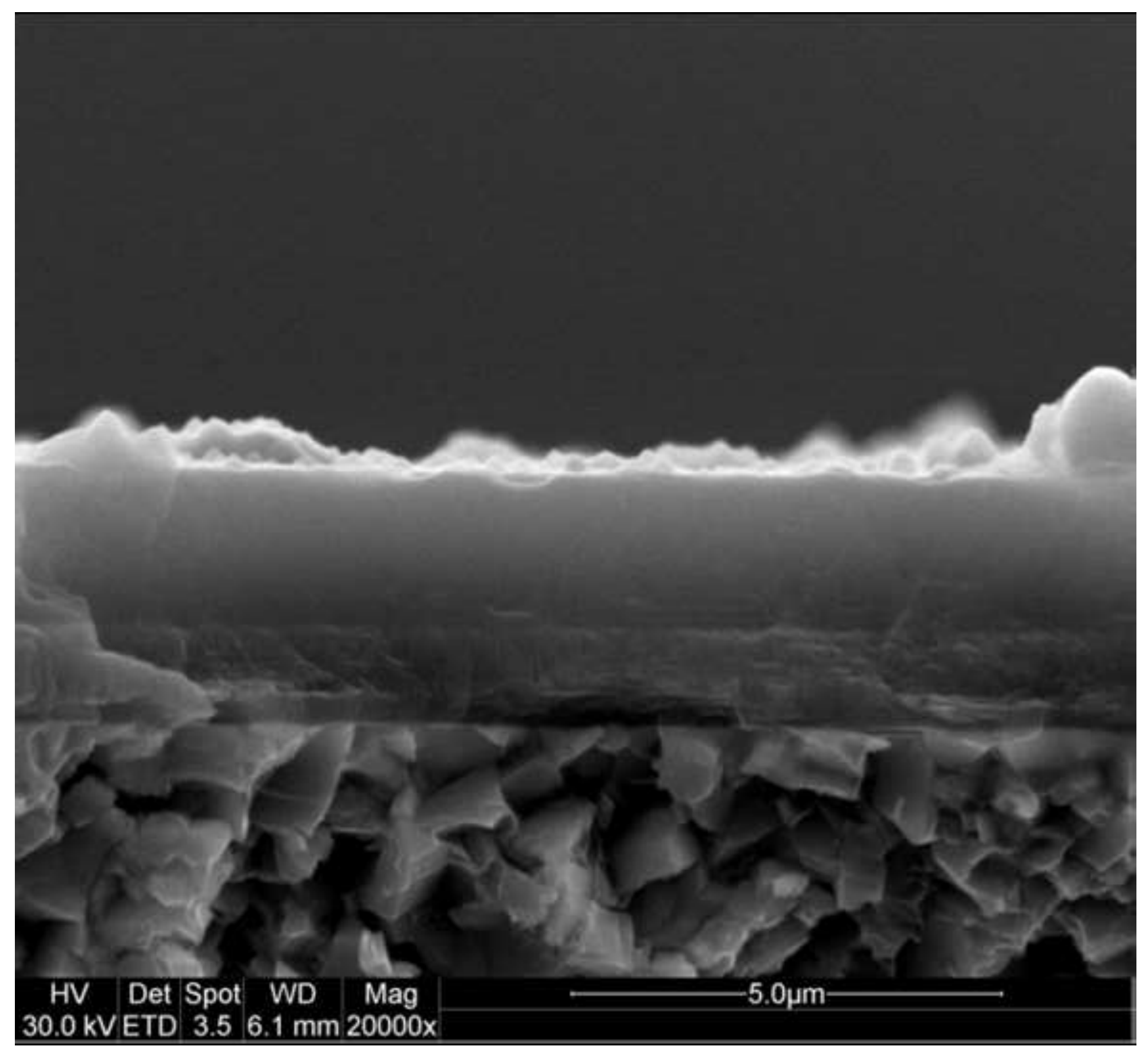




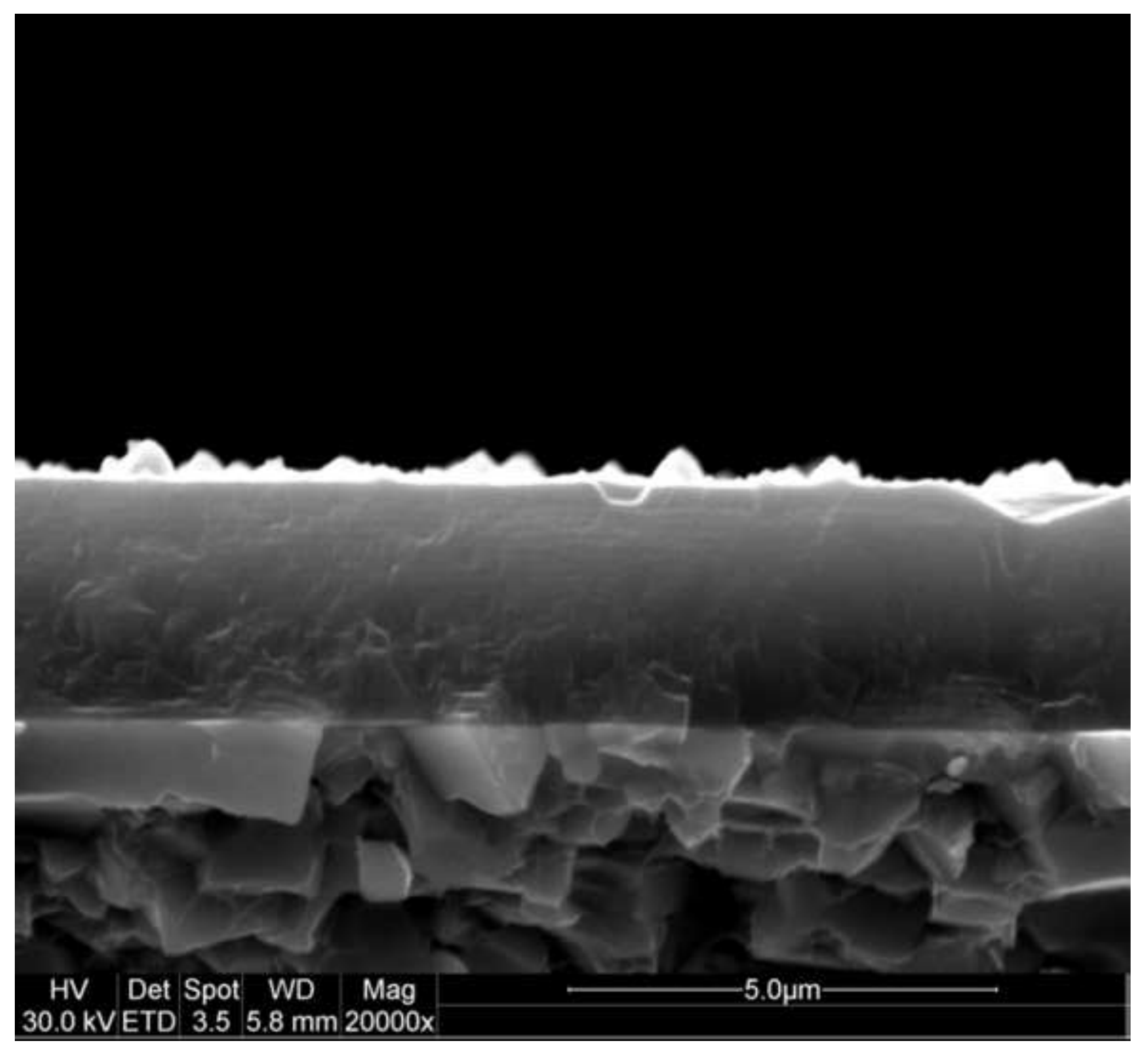

30.0 kVETD $3.55 .8 \mathrm{~mm} 20000 \mathrm{x}$

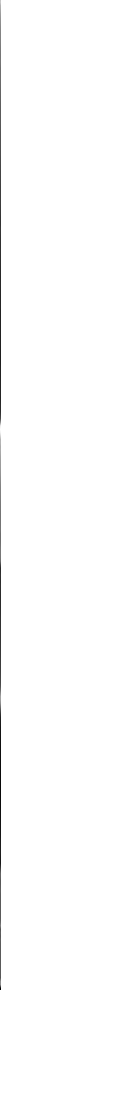




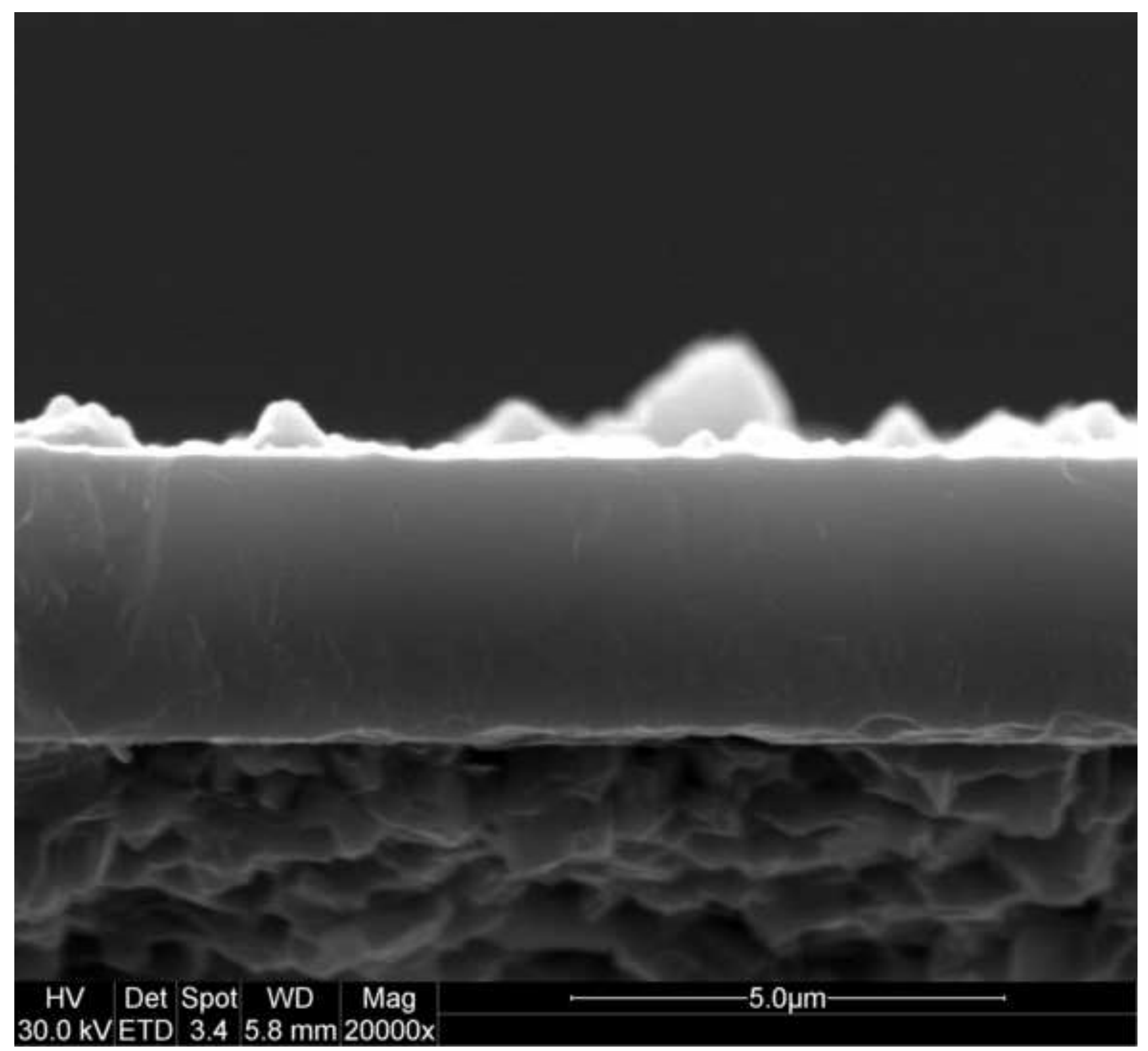

30.0 kVETD $3.4 \quad 5.8 \mathrm{~mm} 20000 \mathrm{x}$ 
Fig. 3. Oxide nodules on used $\mathrm{AICr} 70: 30$ at $\%$ cathode.

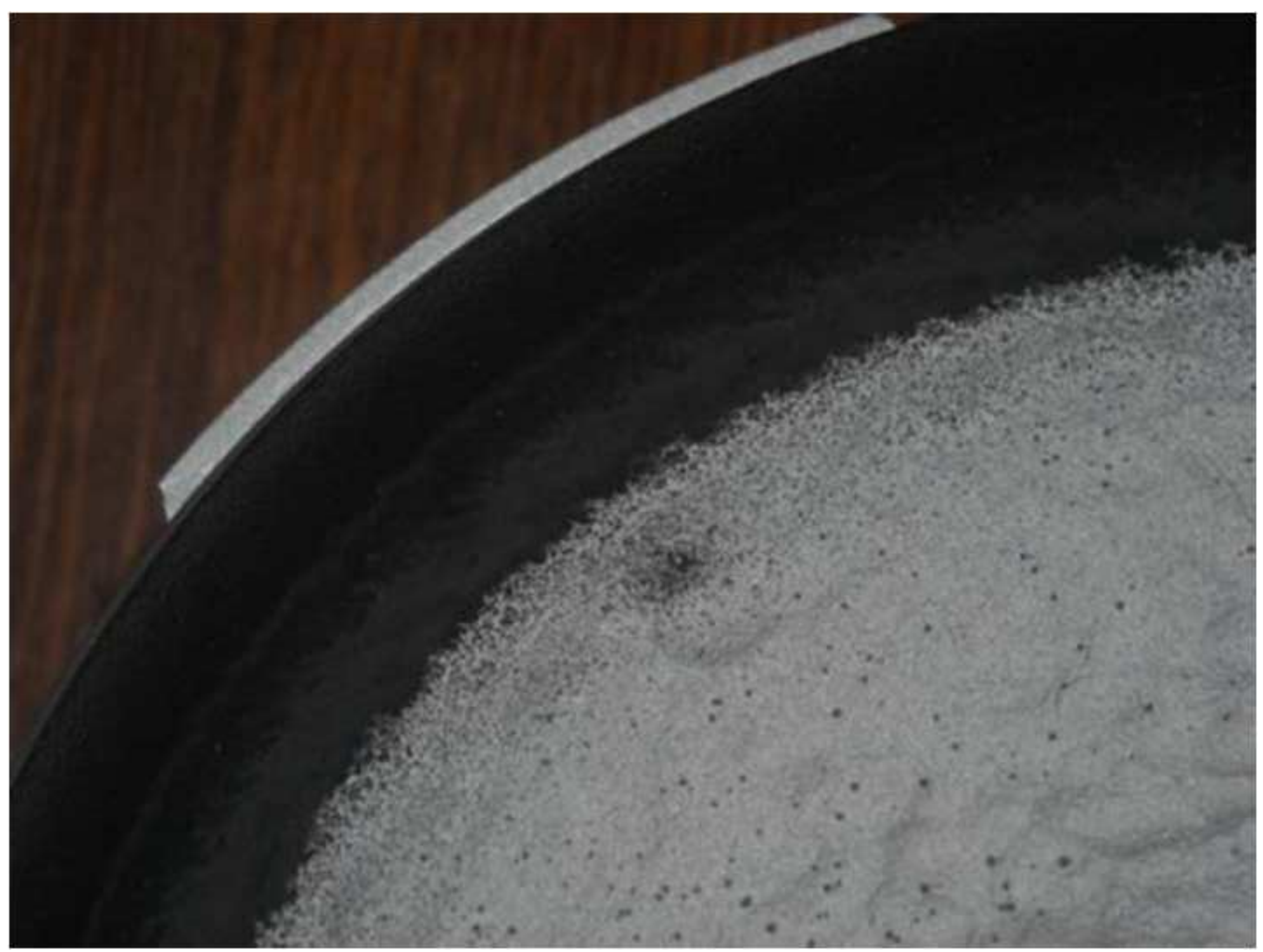




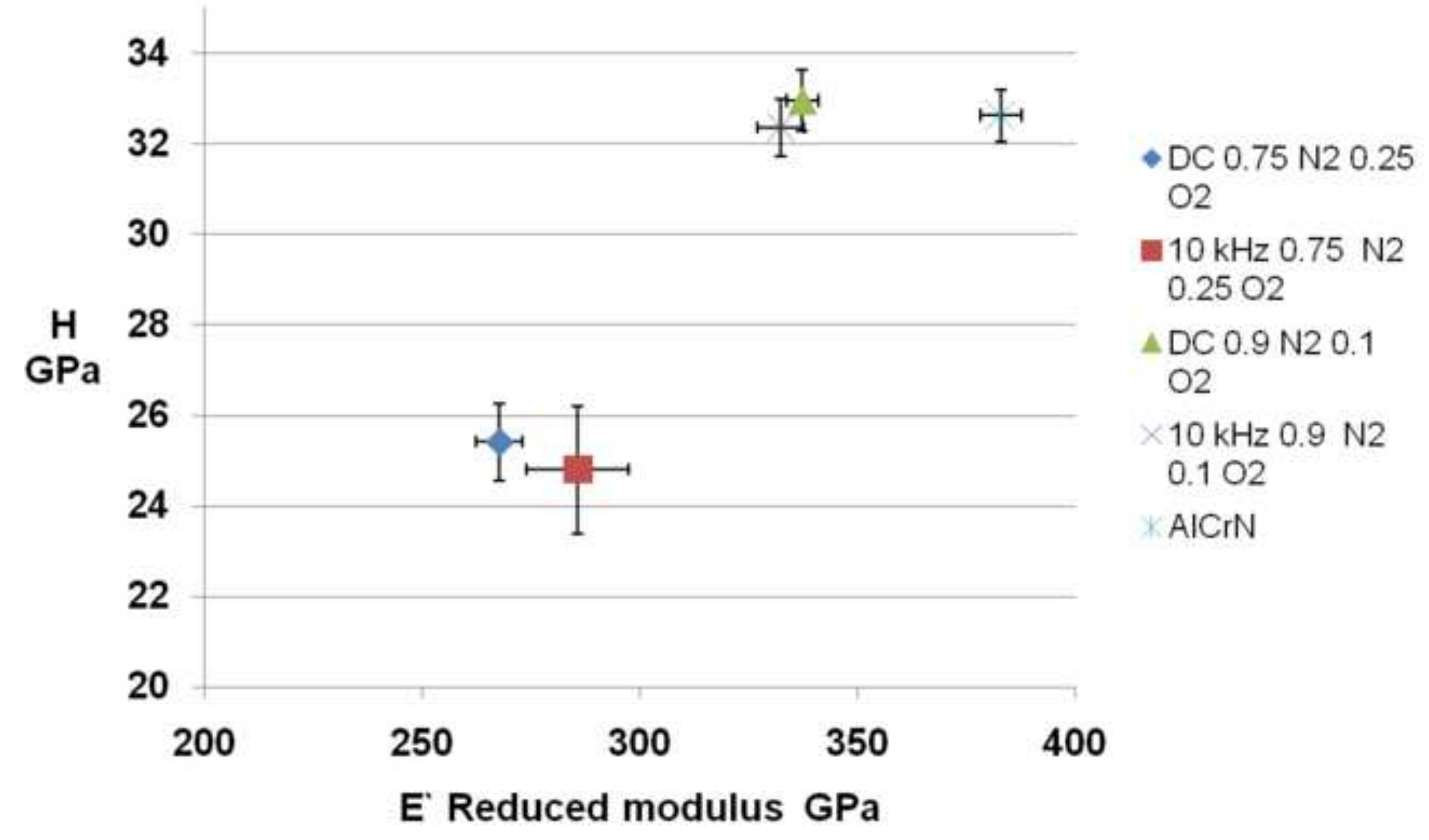




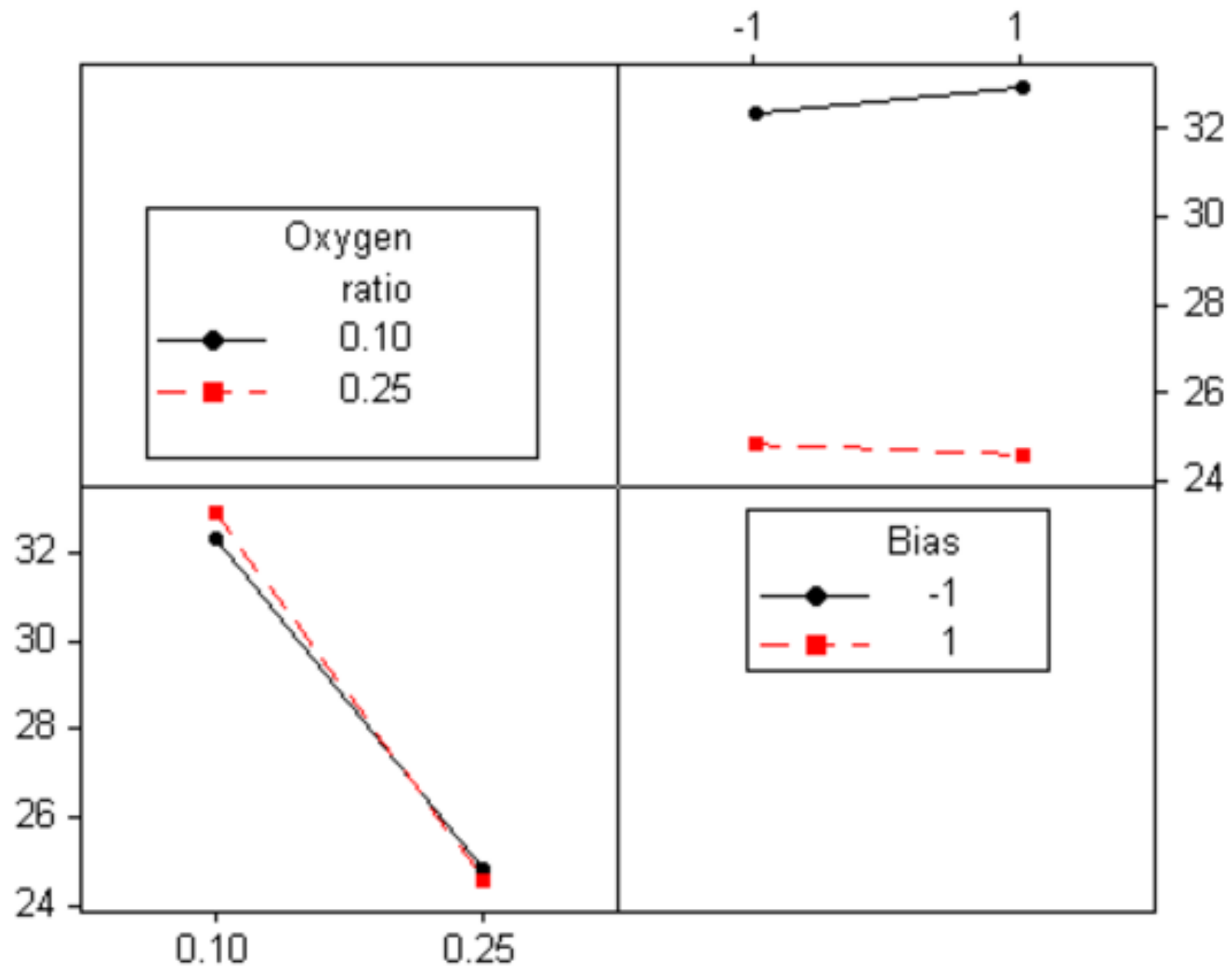


Fig. 5(b). Interaction plot for E.

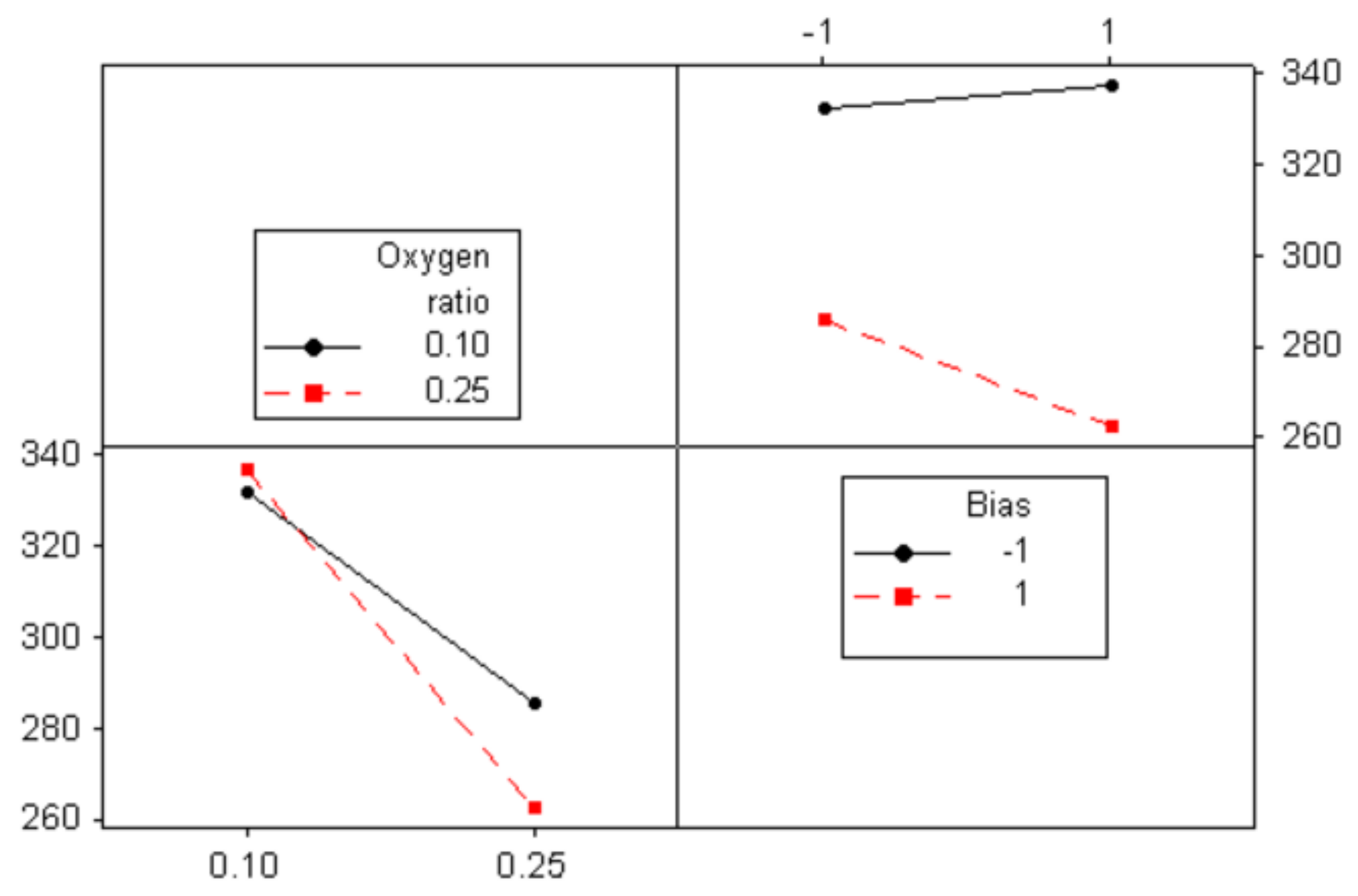




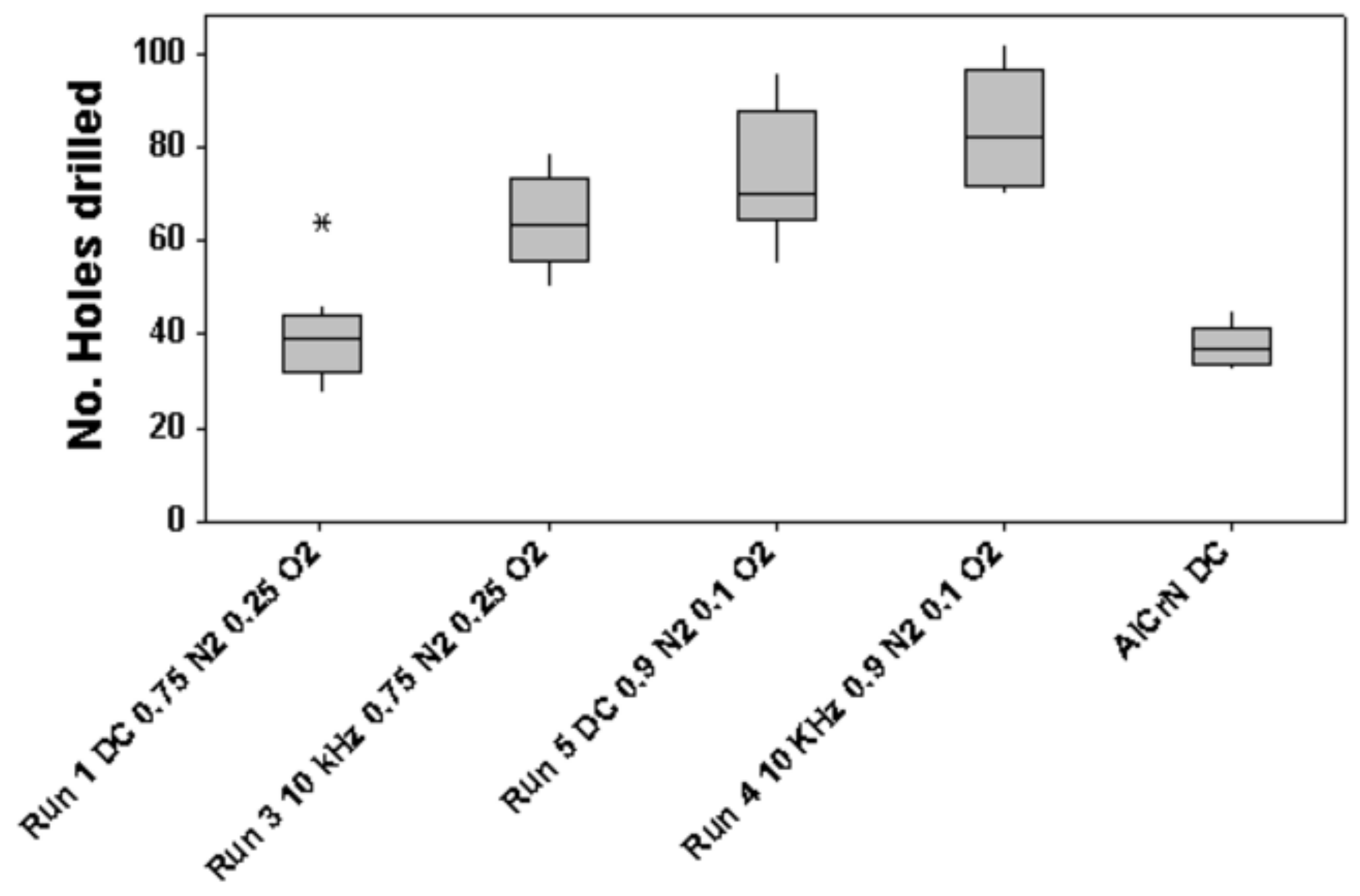




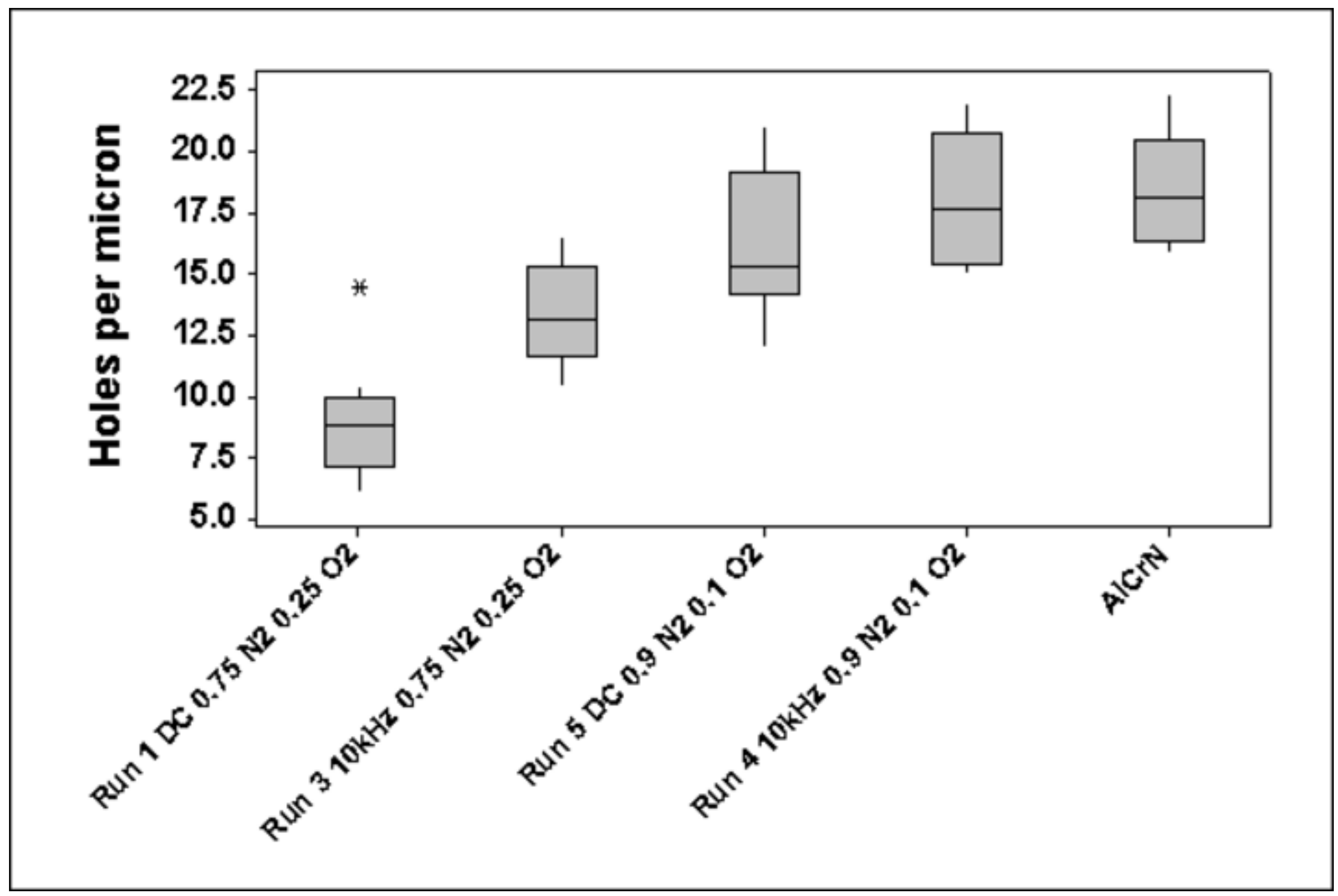




\section{Interaction Plot for holes imicron}

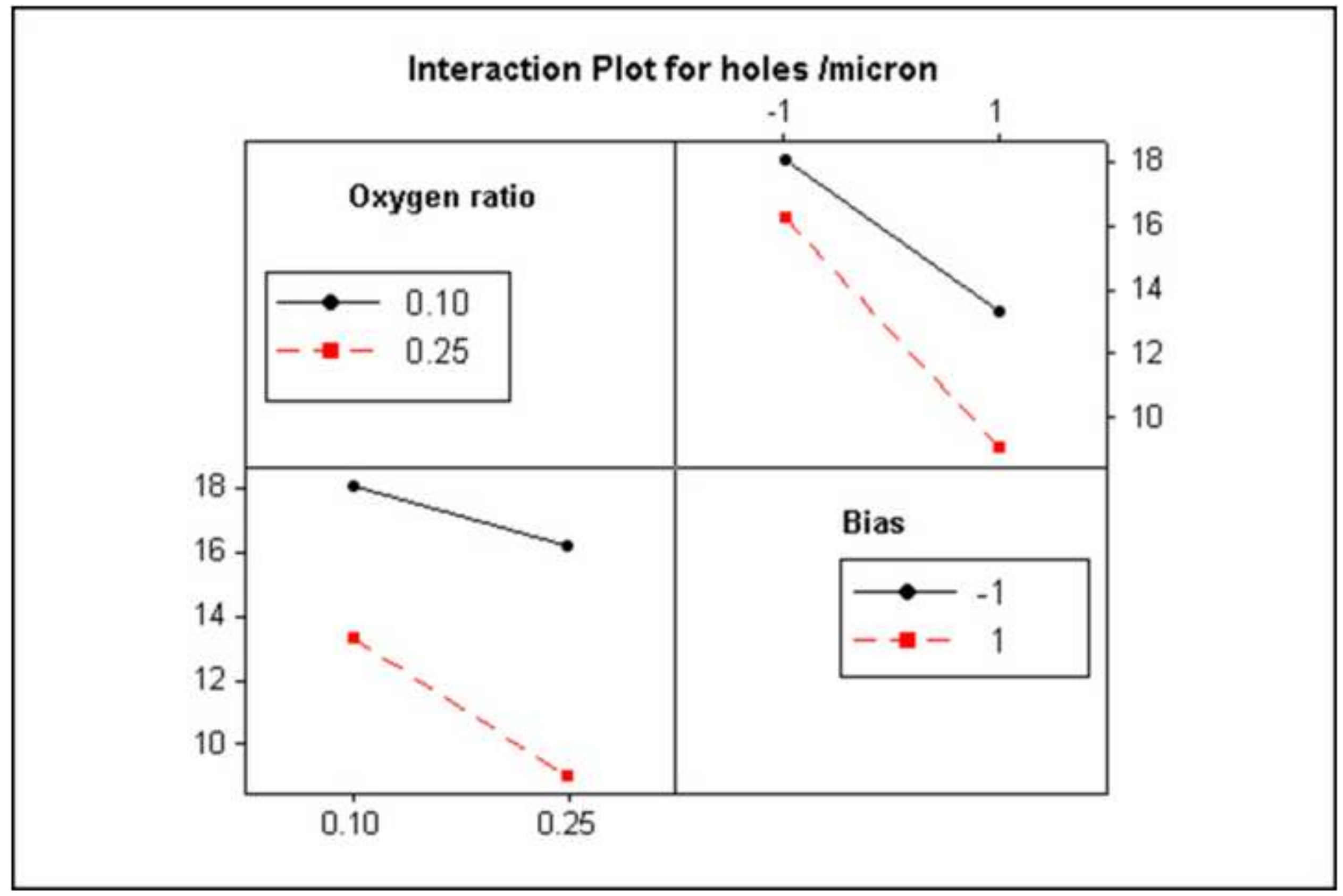


Fig. 7(b). Run 410 kHz 0.9 N2 0.102 drill lip after 30 holes.

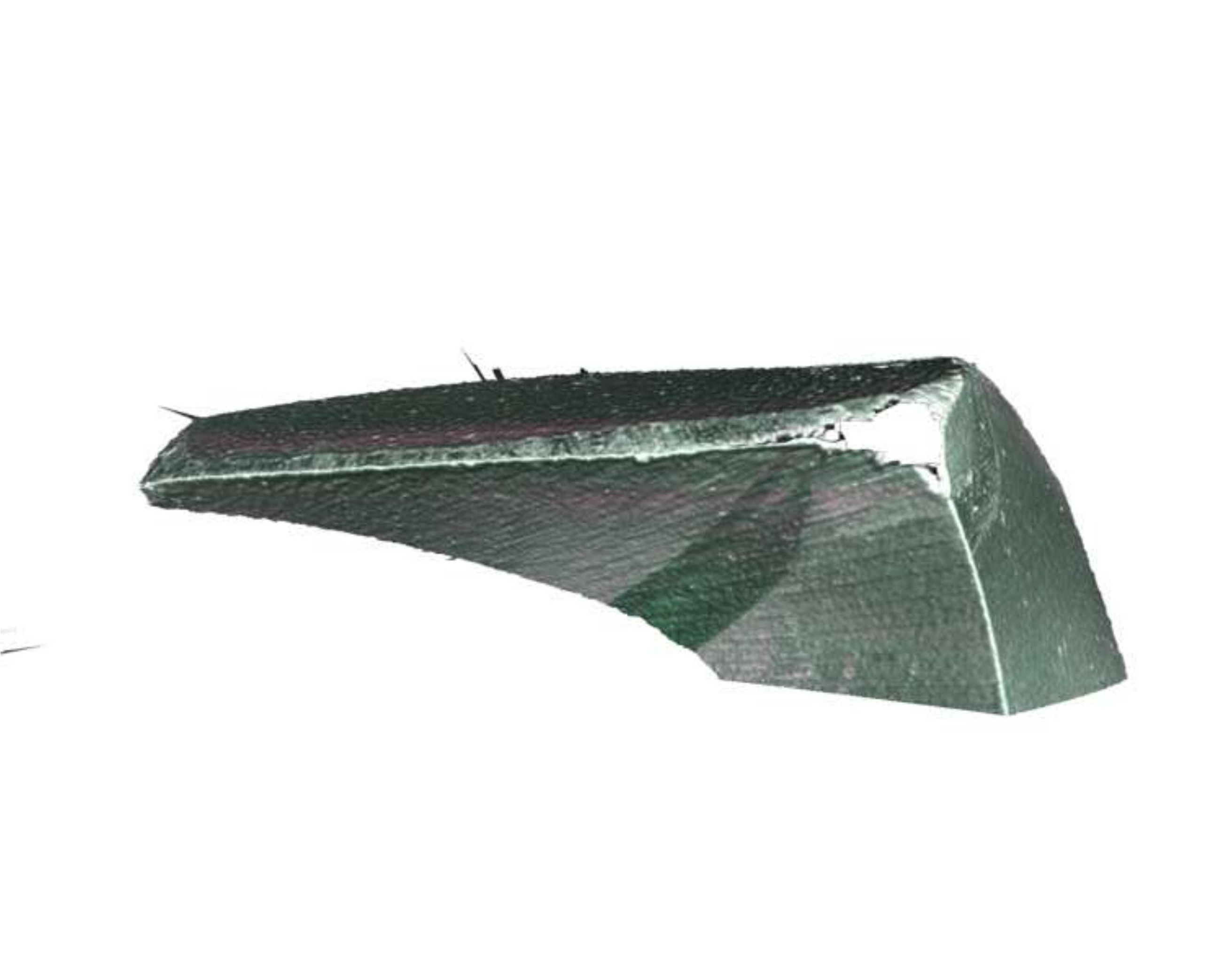

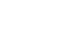

\section{.}
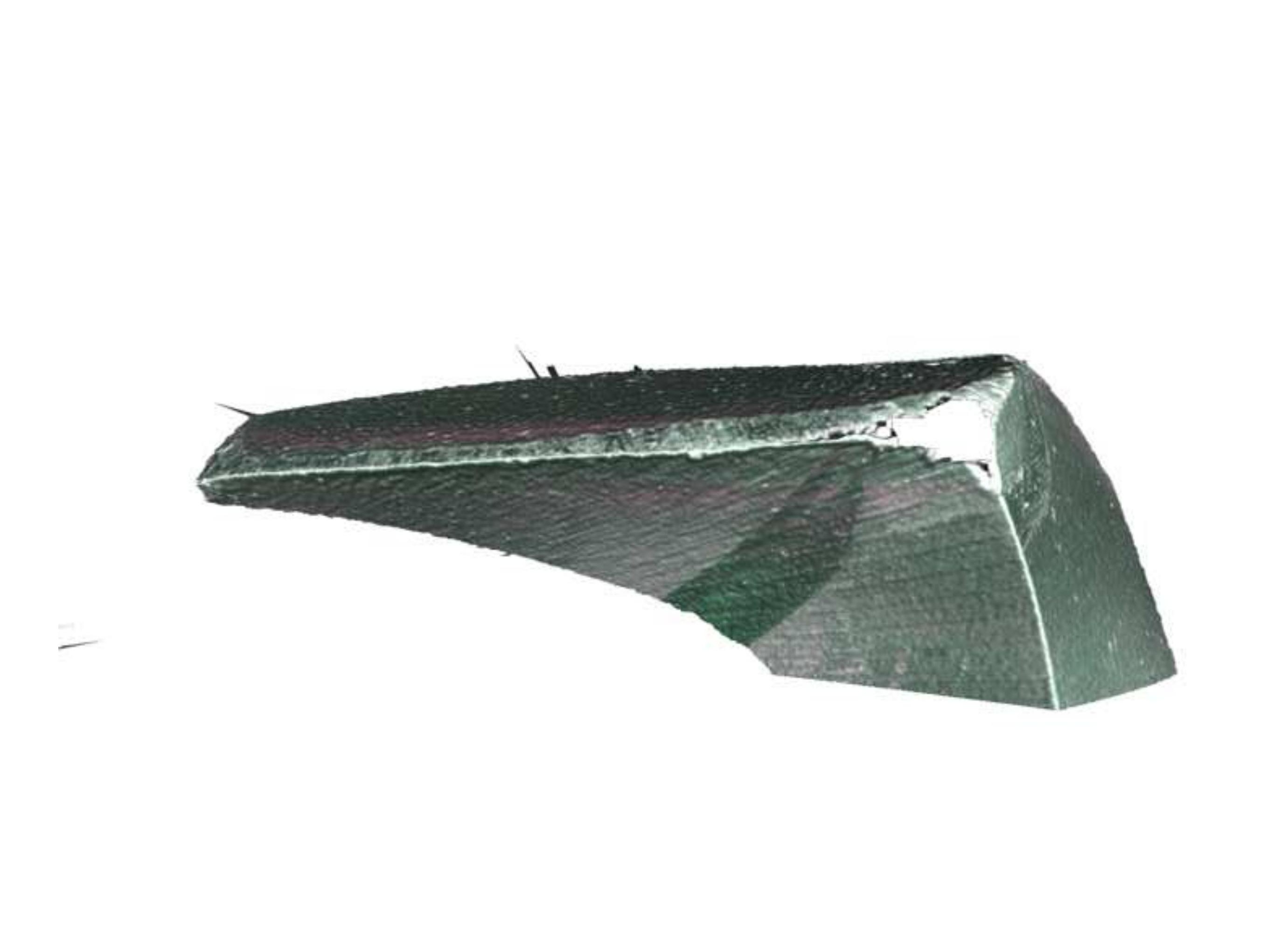

. 


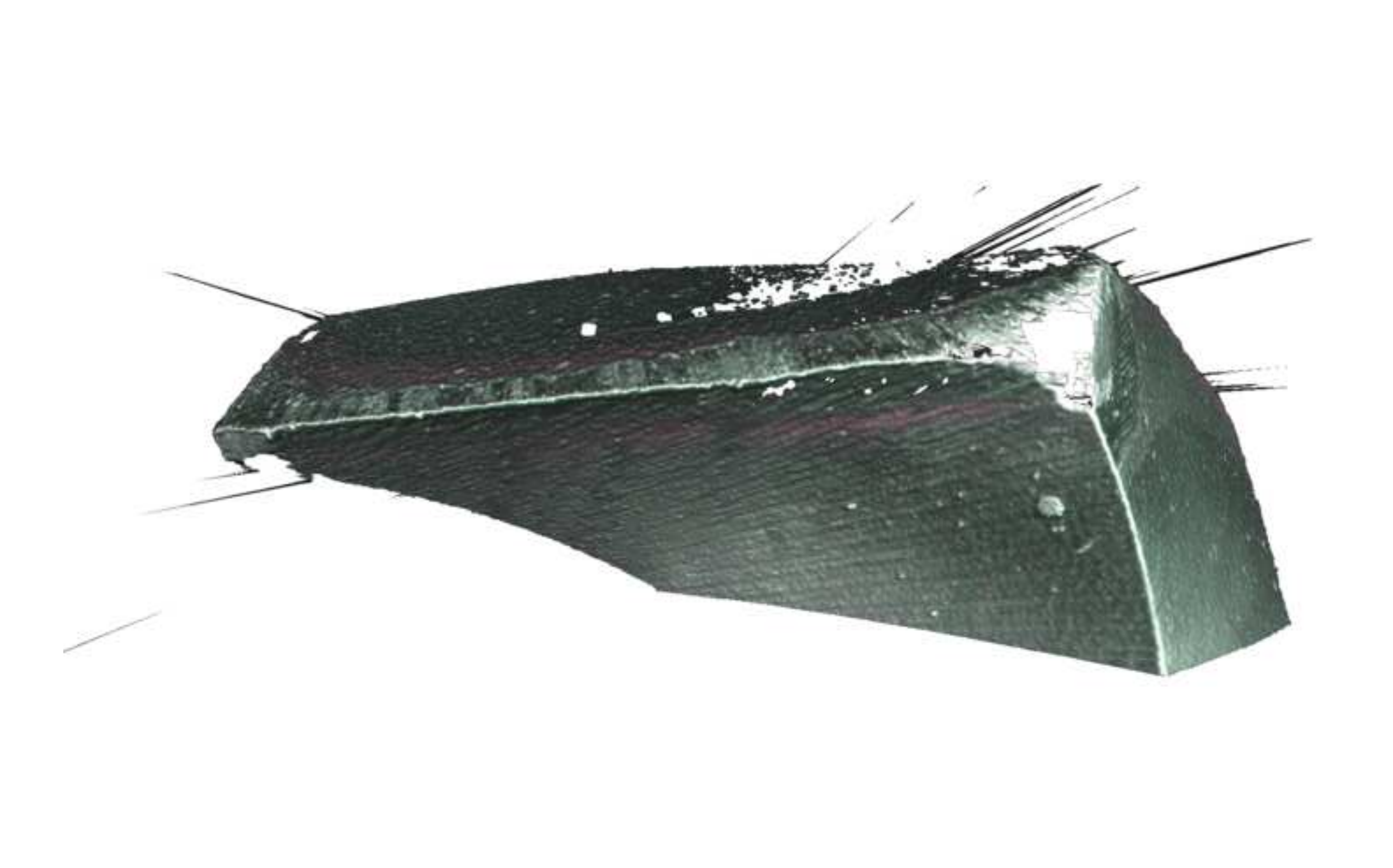




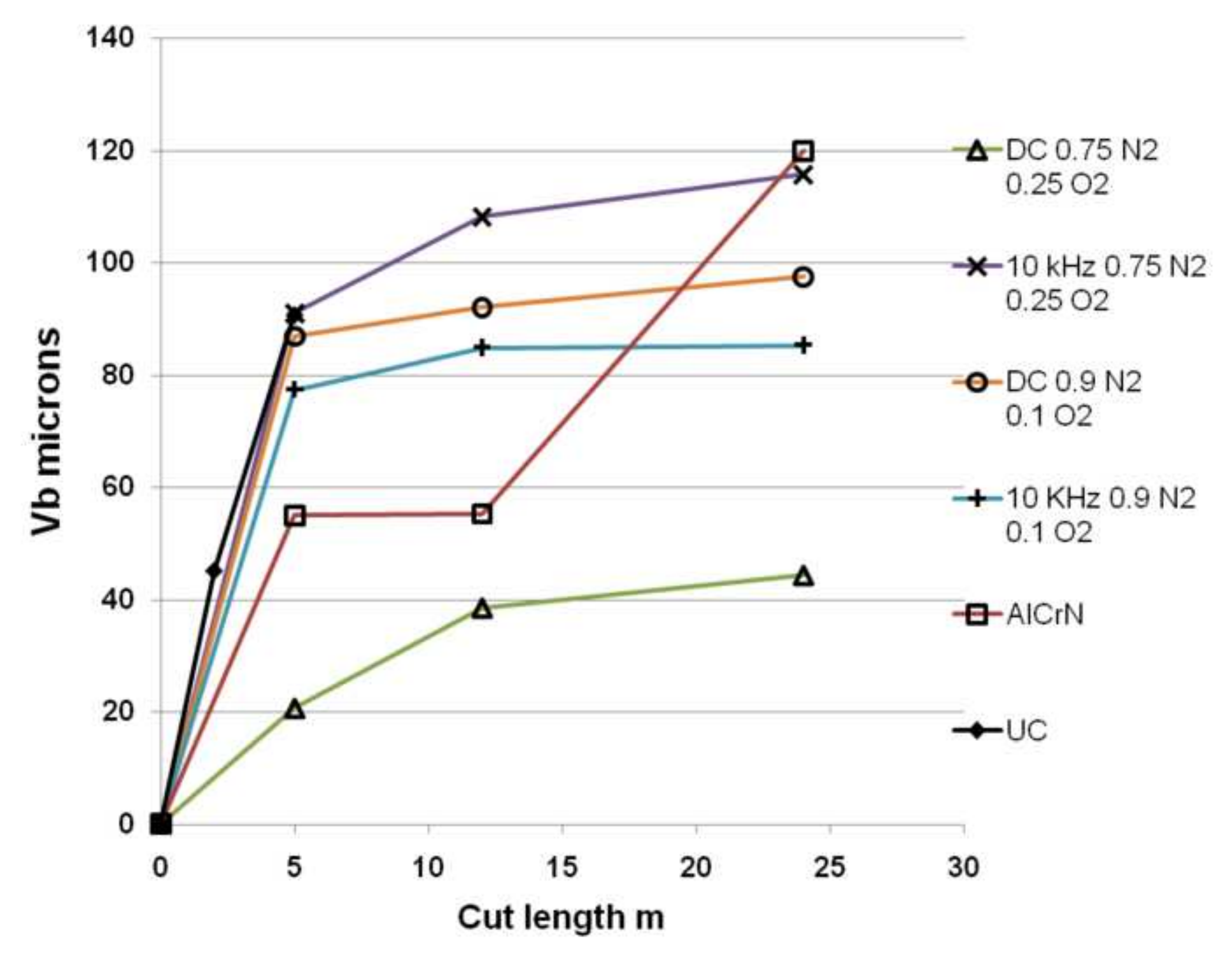

Fig. 8. Plot of $4 \mathrm{~mm}$ end mill corner wear $\mathrm{Vb}$ machining AISI316L 


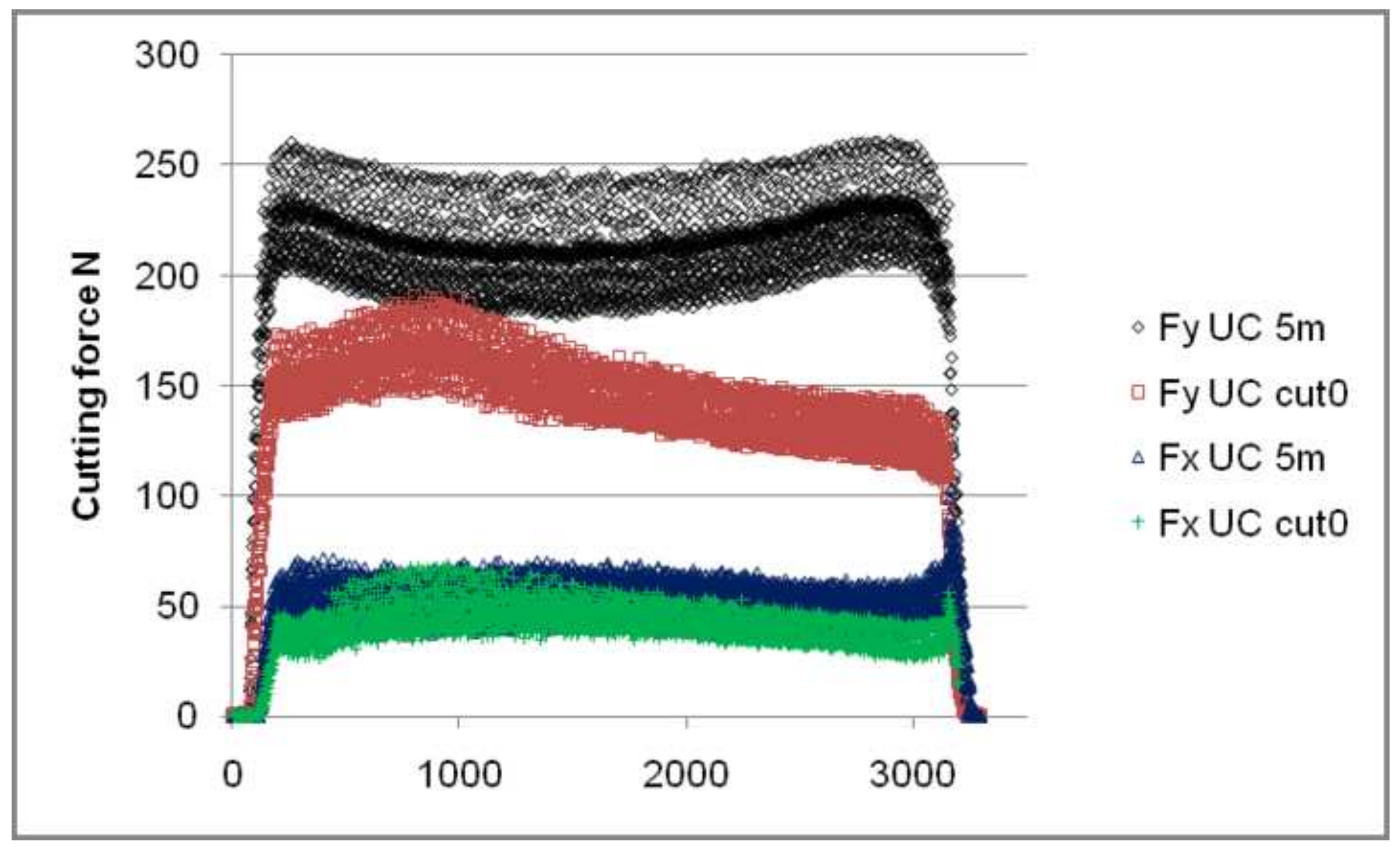

- Fy UC cutO

$\triangle \mathrm{Fx}$ UC $5 \mathrm{~m}$

+ Fx UC cutO 


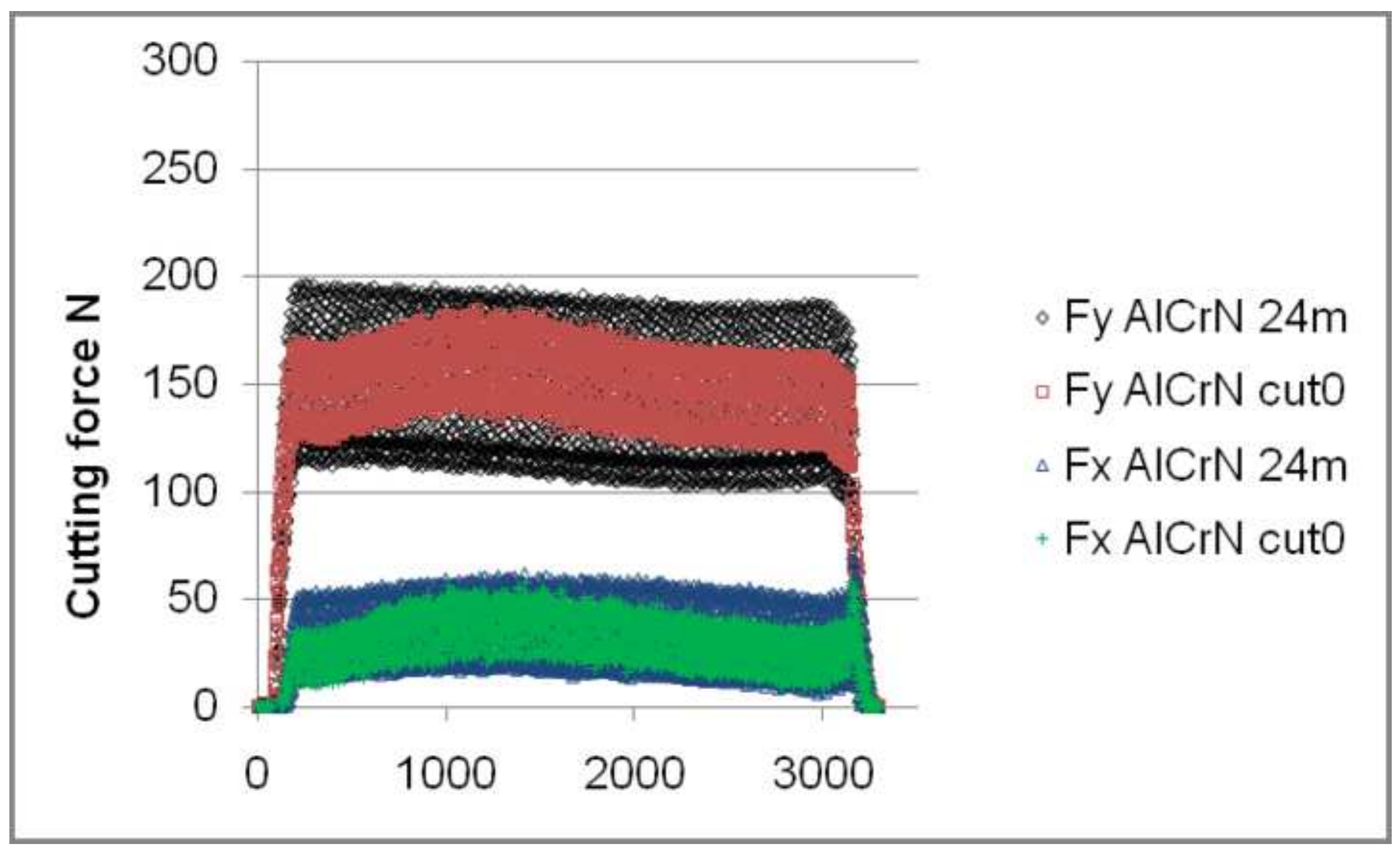

- Fy AlCrN 24m

- Fy AlCrN cutO

$\triangle \mathrm{Fx}$ AICrN 24m

- Fx AICrN cutO 


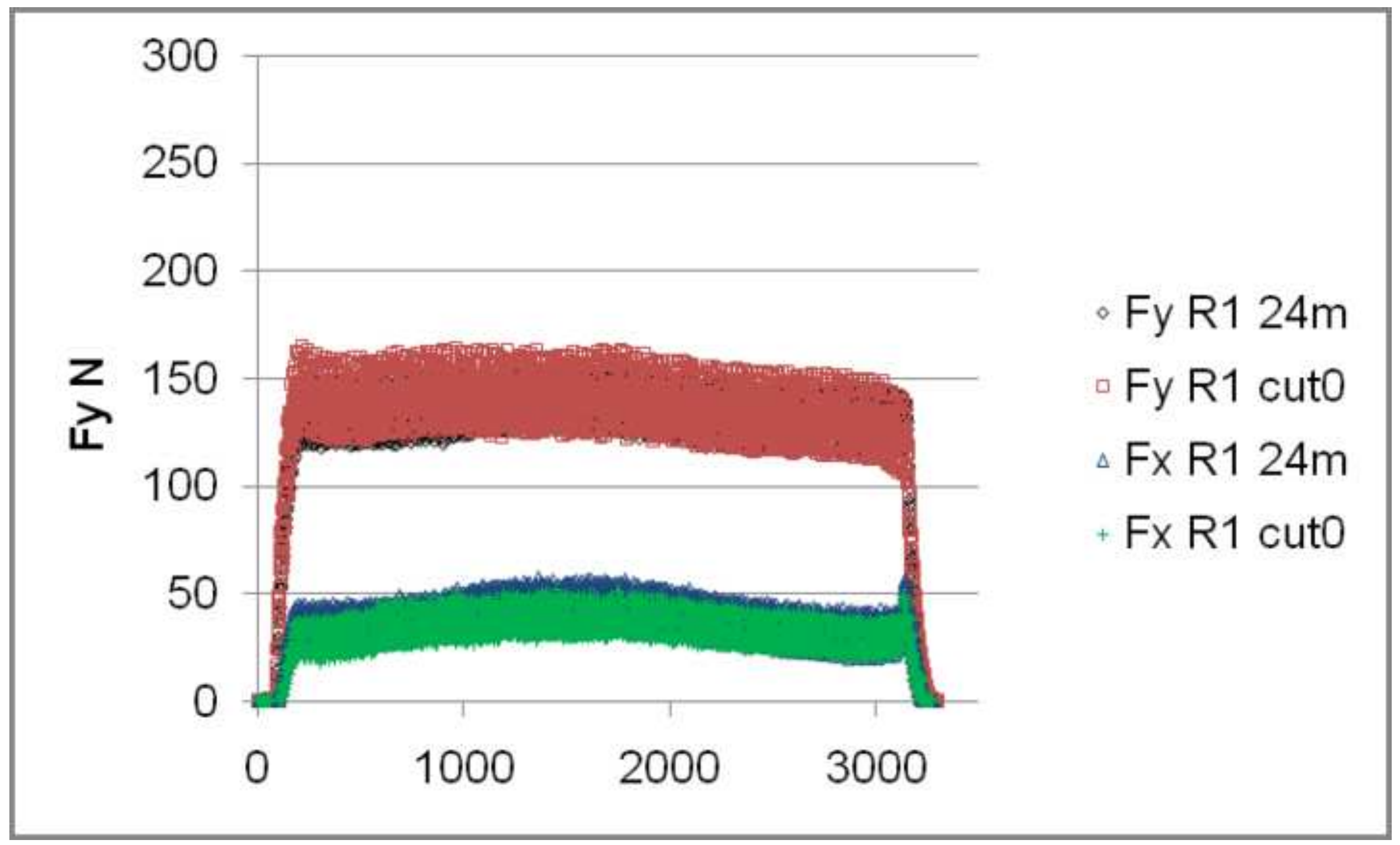




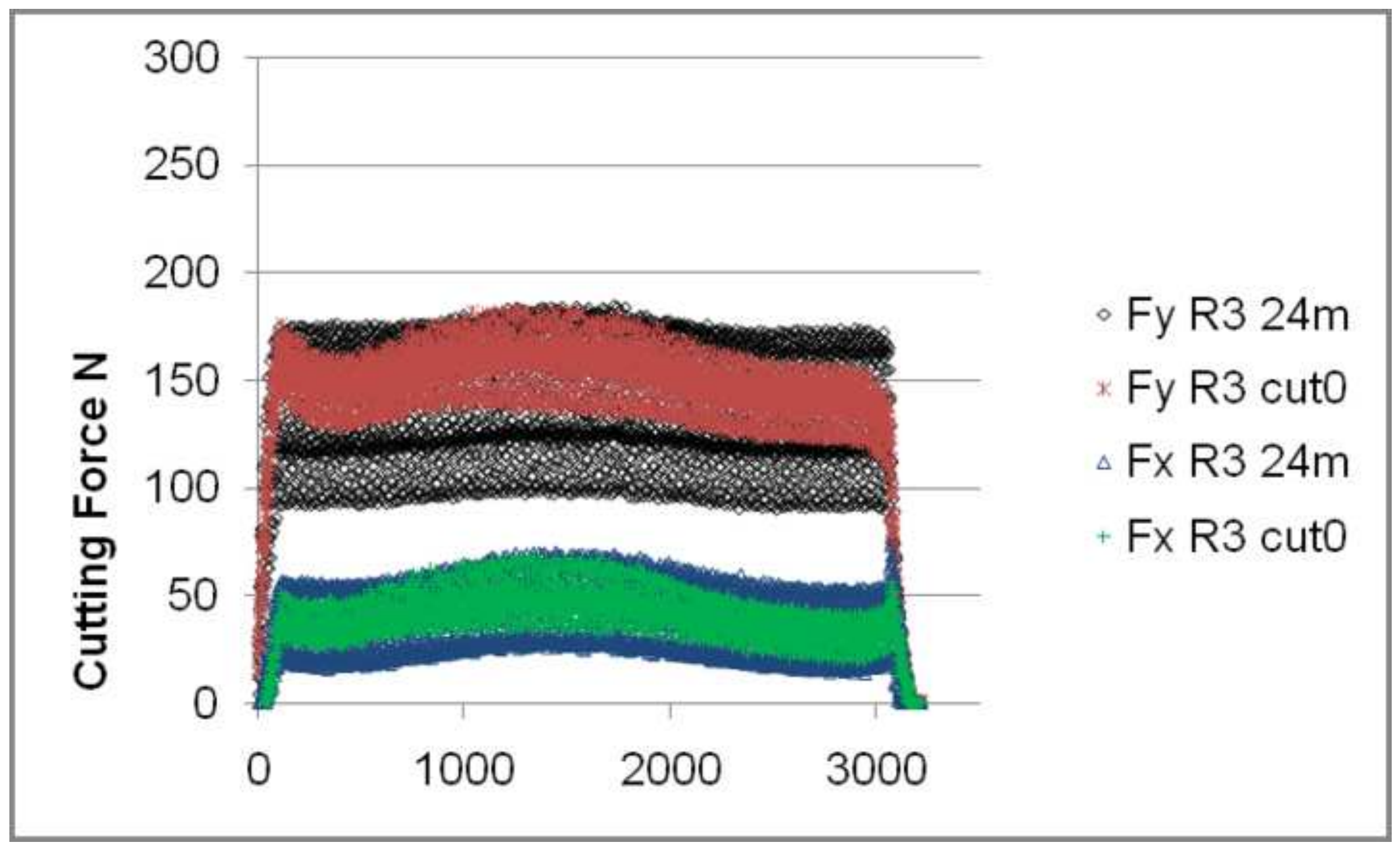

- Fy R3 24m

* Fy R3 cuto

$\triangle F x$ R3 24m

Fx R3 cuto 


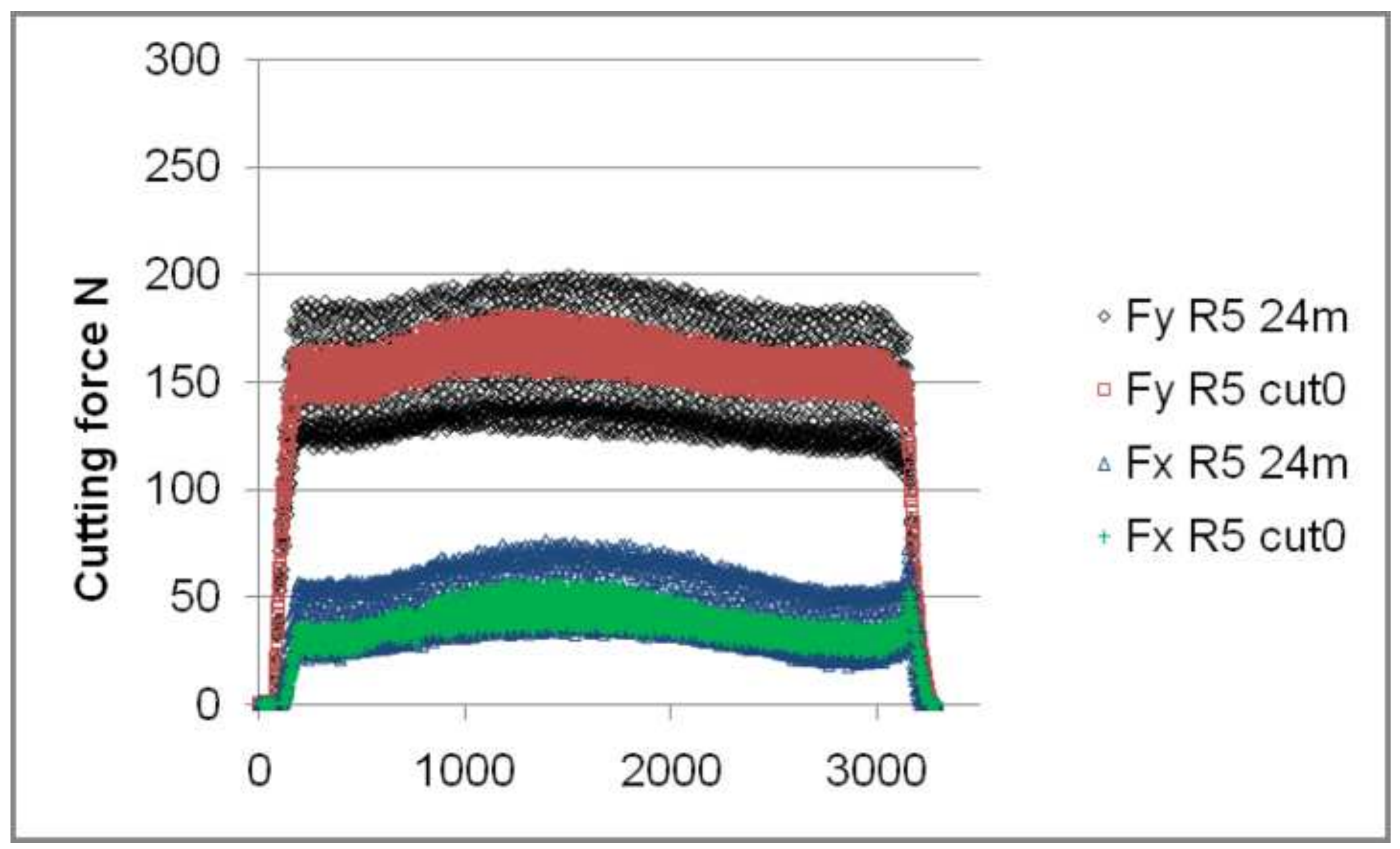

- Fy R5 24m

- Fy R5 cut0

$\triangle F x$ R5 24m

+ Fx R5 cuto 


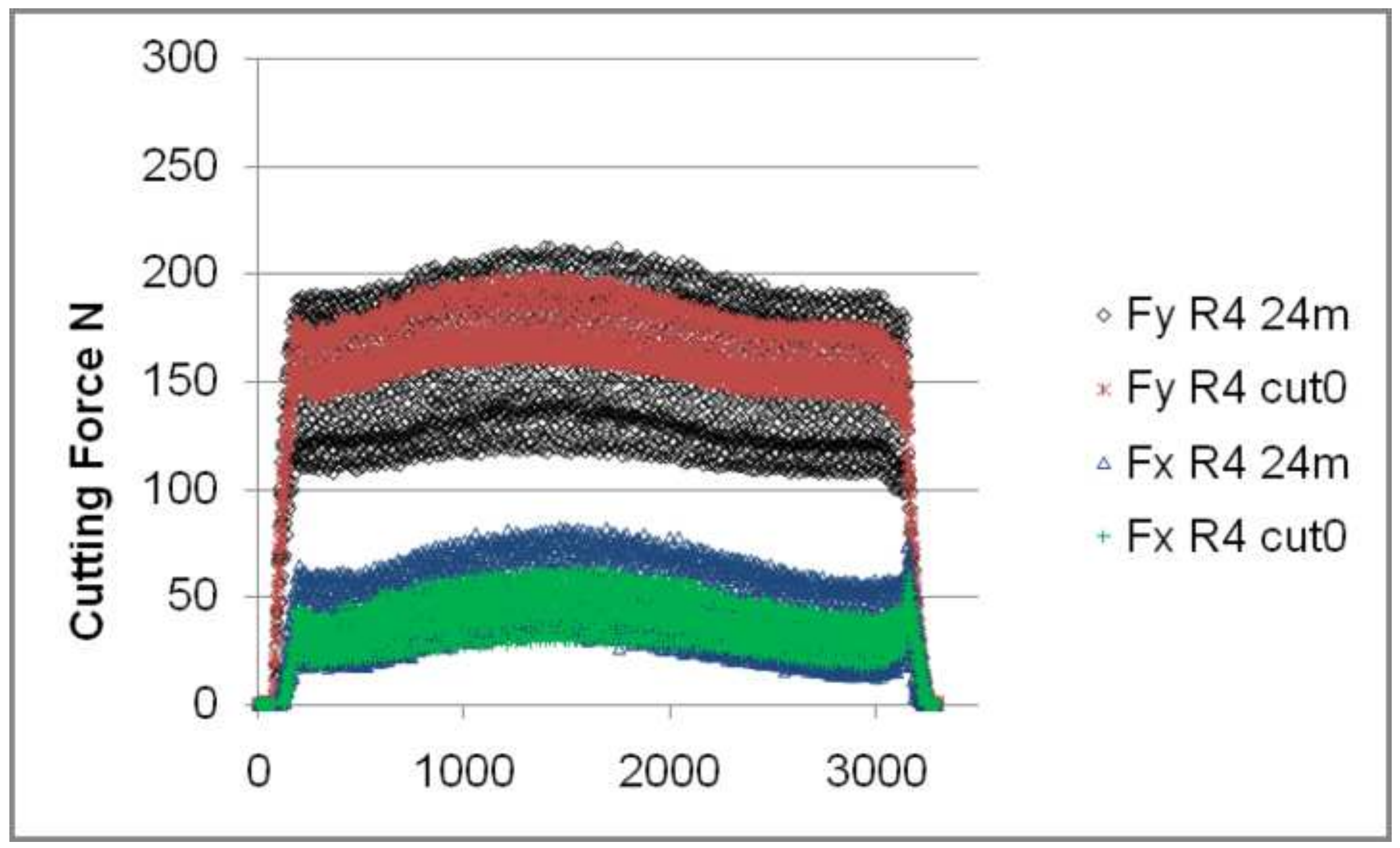




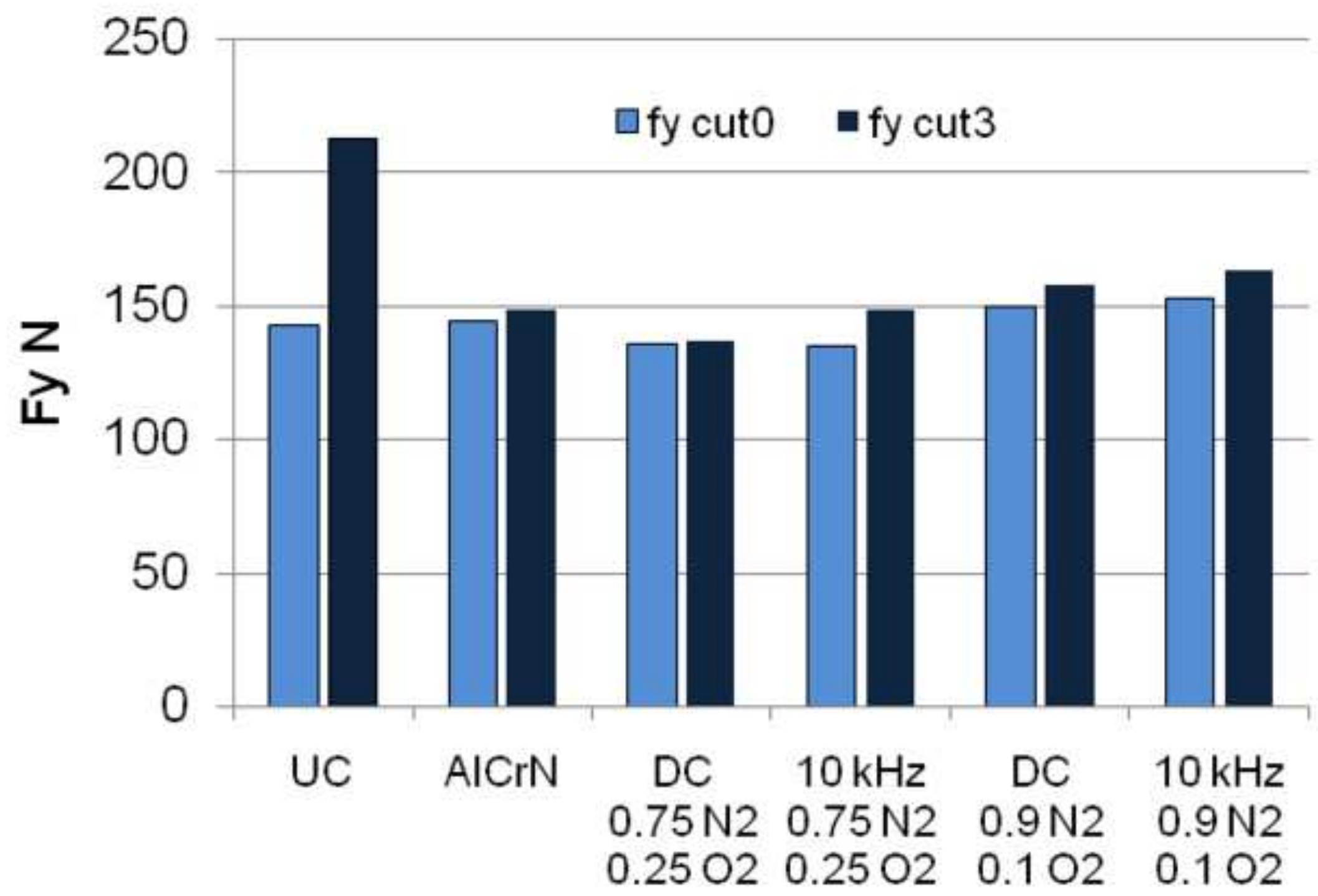




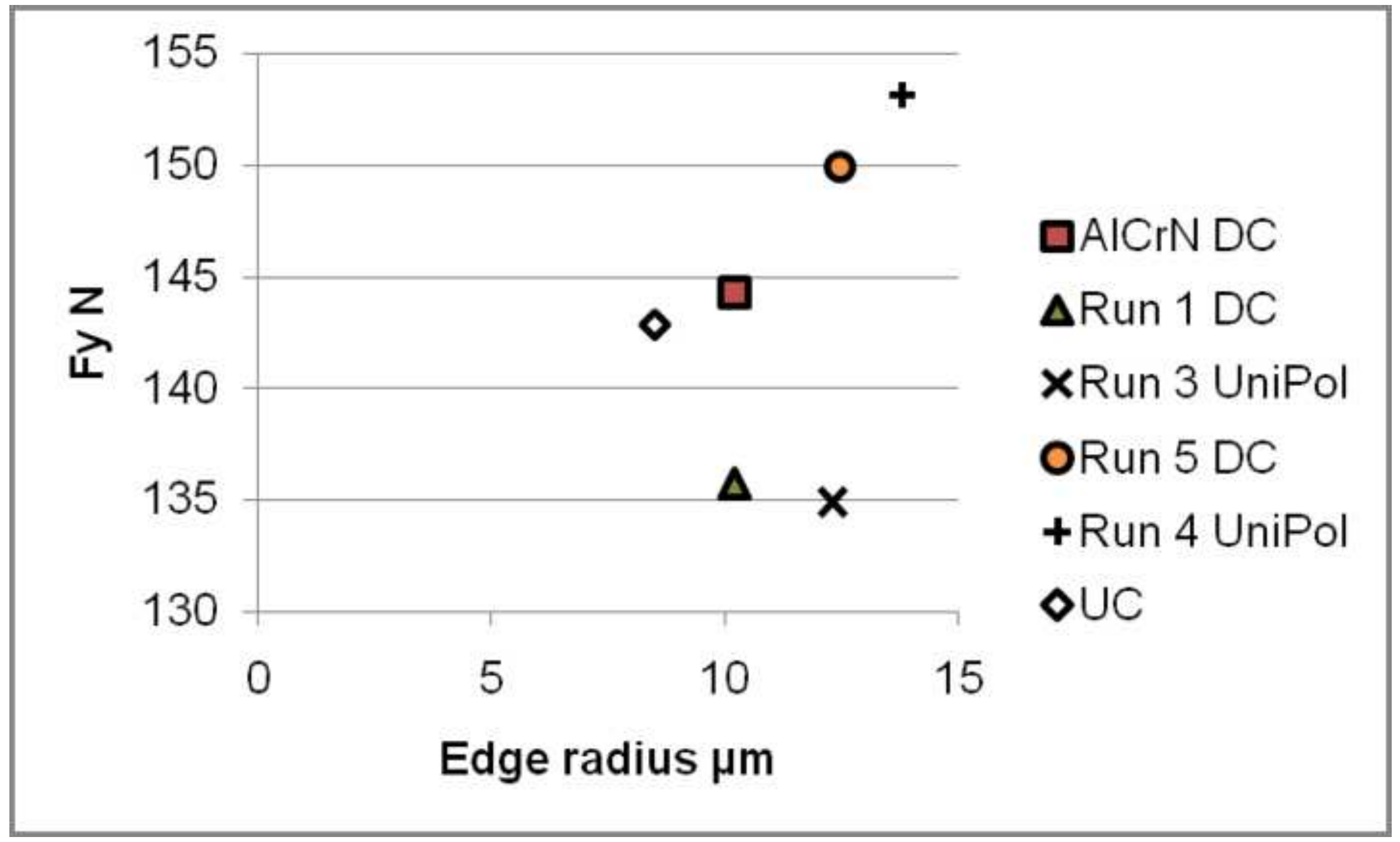




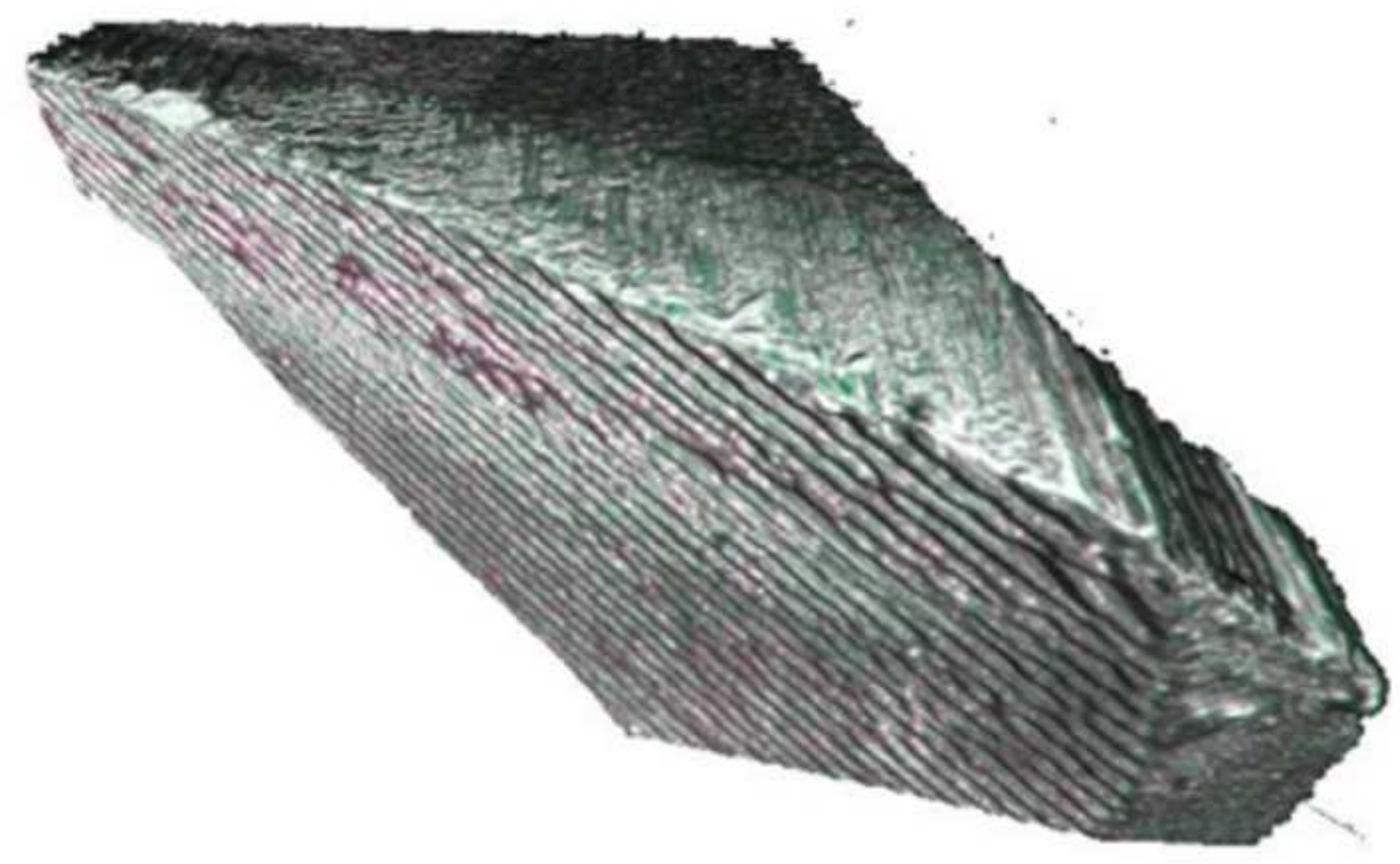

Fig. 12(b). UC after $5 \mathrm{~m}$ cut length.

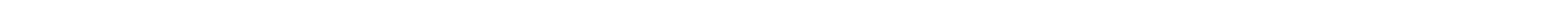

r

\author{
Fig. $12(b) . U C$ after $5 \mathrm{~m}$ cut length.
}

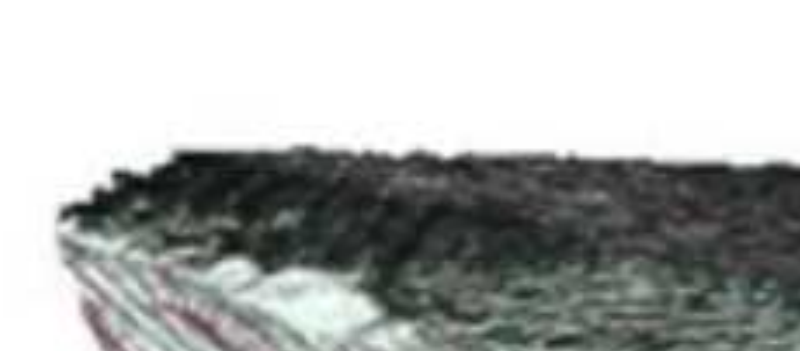

$\frac{3}{3}$ 


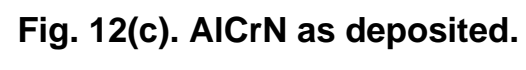
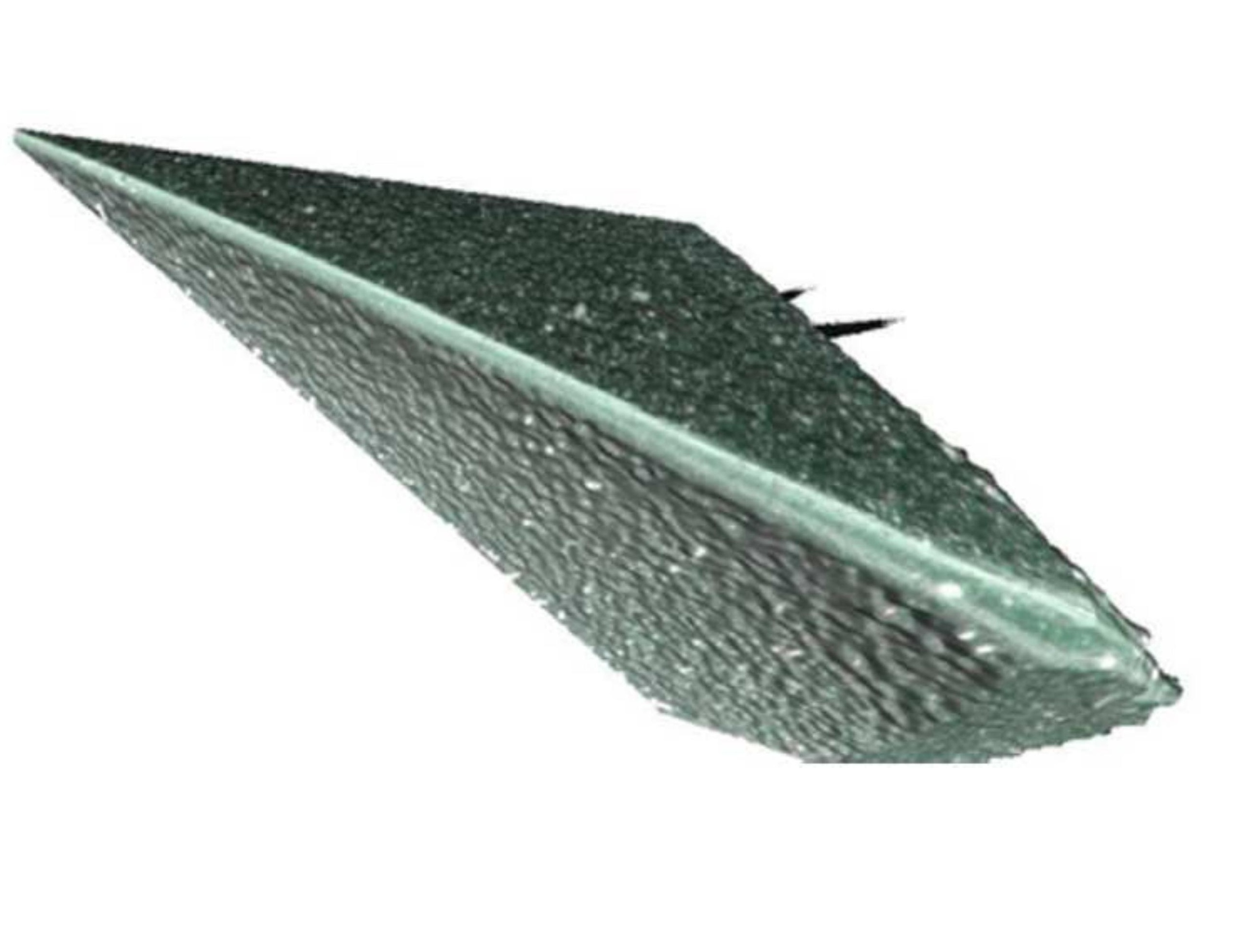
Fig. 12(d). AICrN after $24 \mathrm{~m}$ cut length.

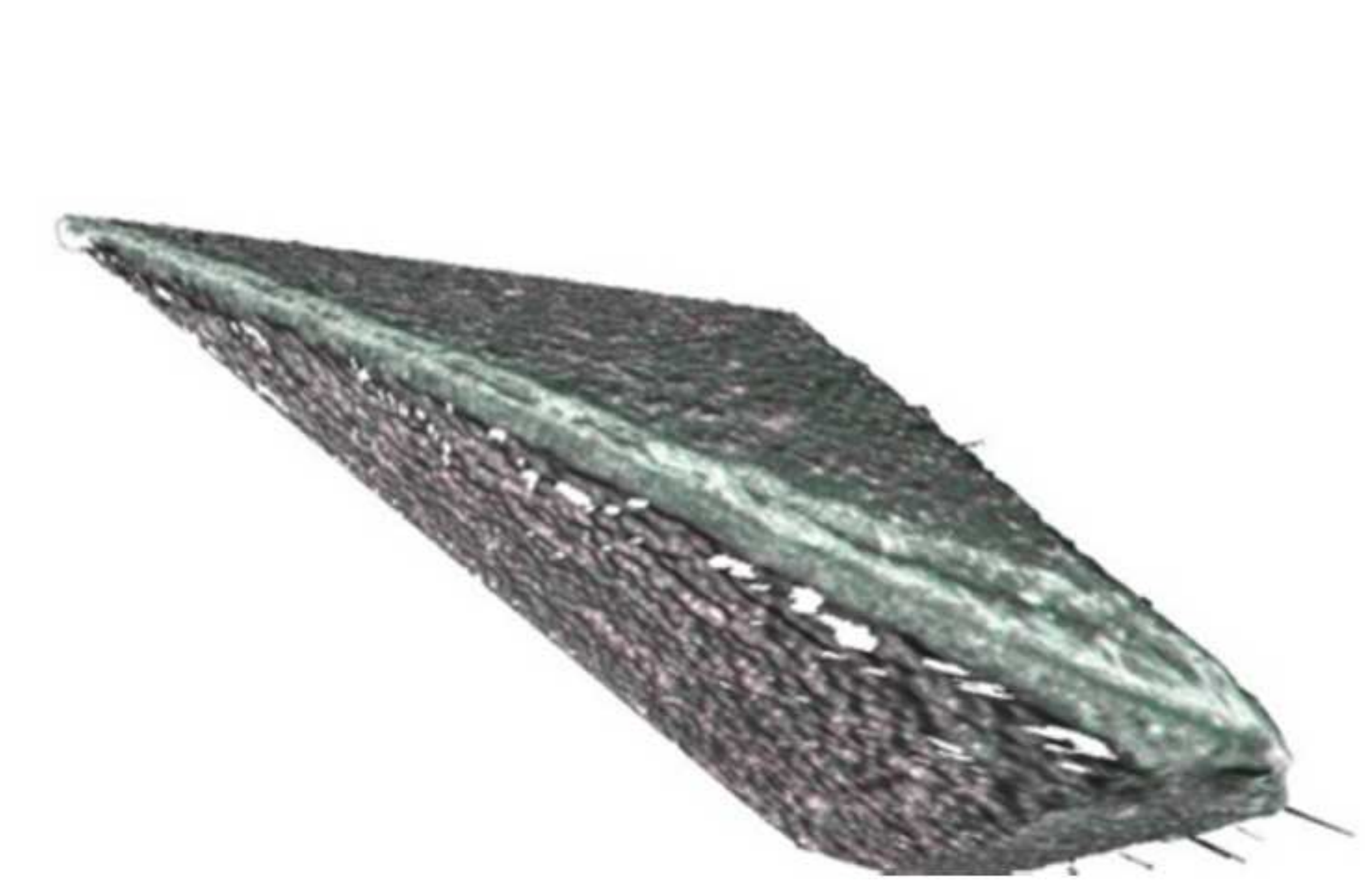

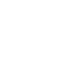 \\ .
}

. 
Fig. $12(e)$. Run 1 after $24 \mathrm{~m}$ cut length.

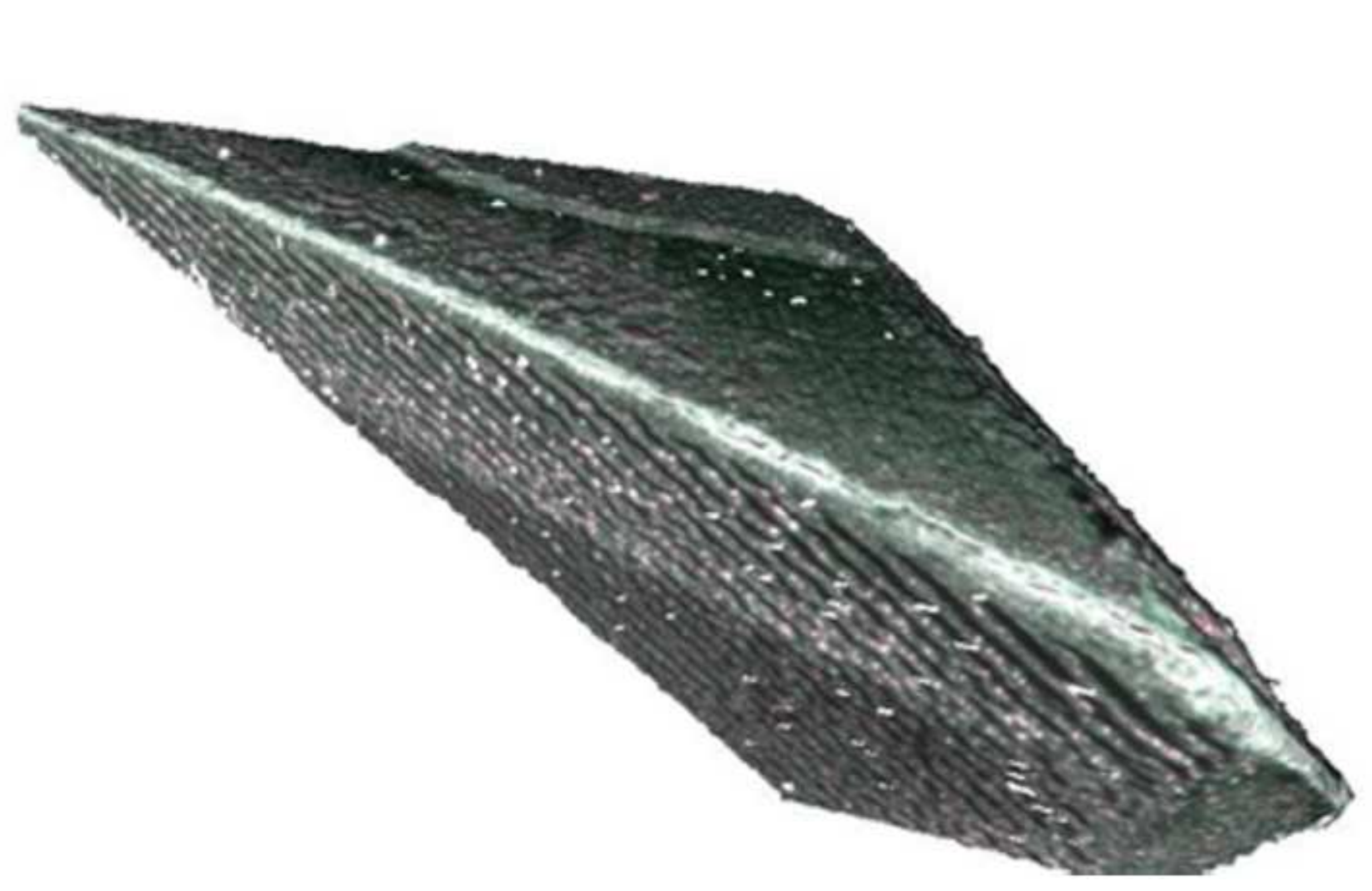

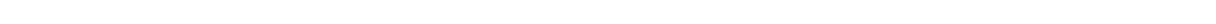


Fig. 12(f). Run 3 after $24 \mathrm{~m}$ cut length.

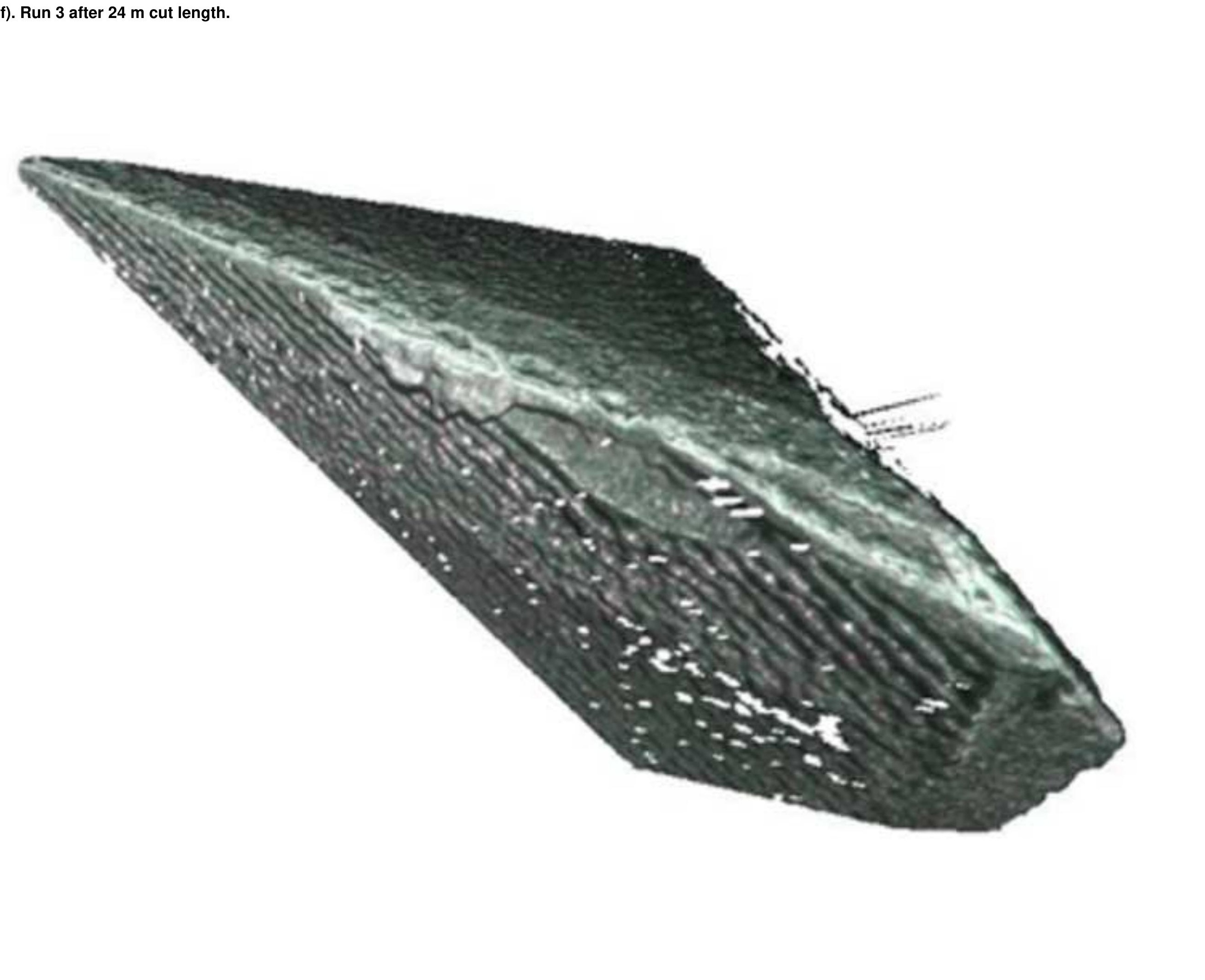

5

$+2=0$

$x=$

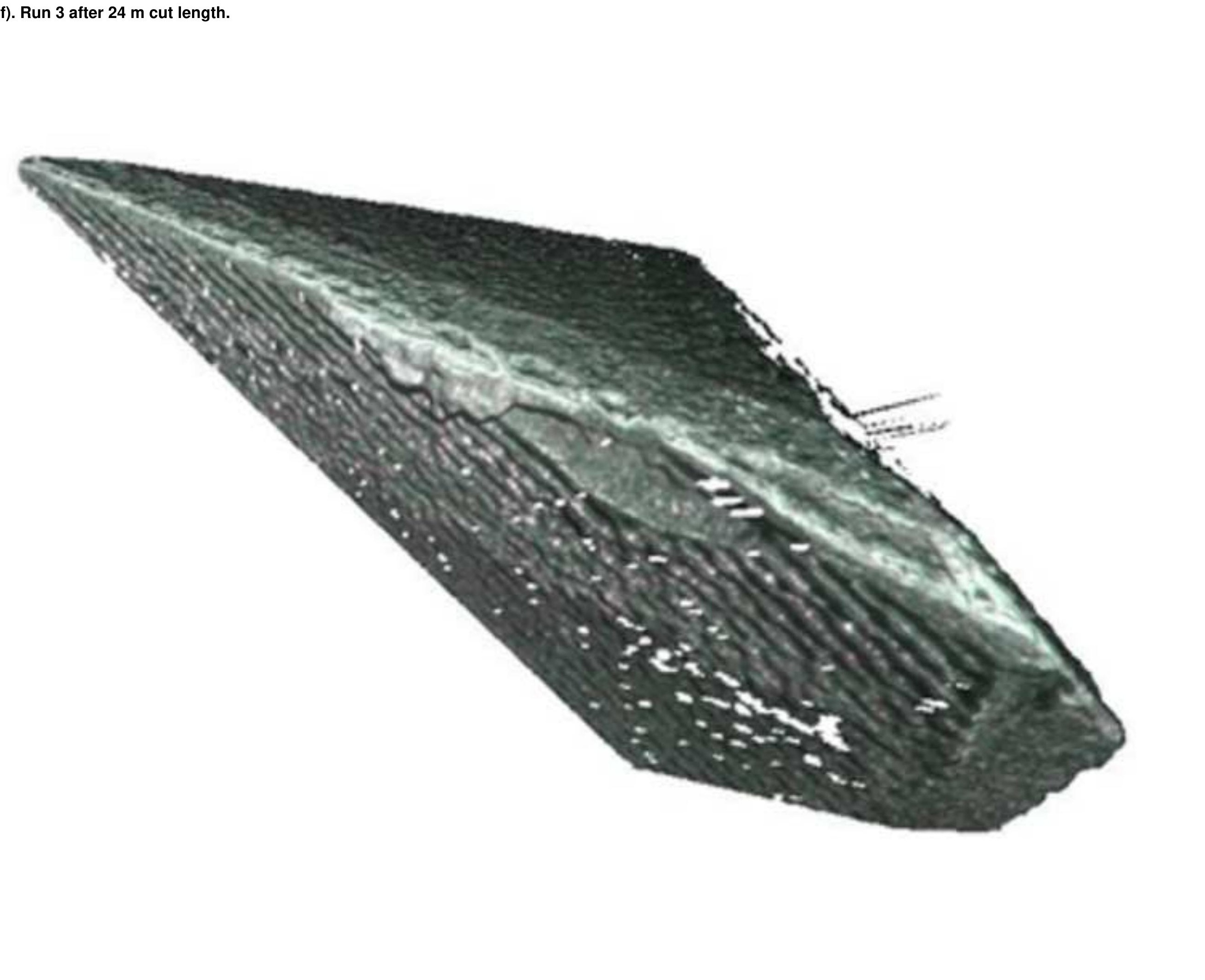

\footnotetext{
.
}


Fig. 13(a). Margin of uncoated endmill after $6.9 \mathrm{~m}$ cut length.

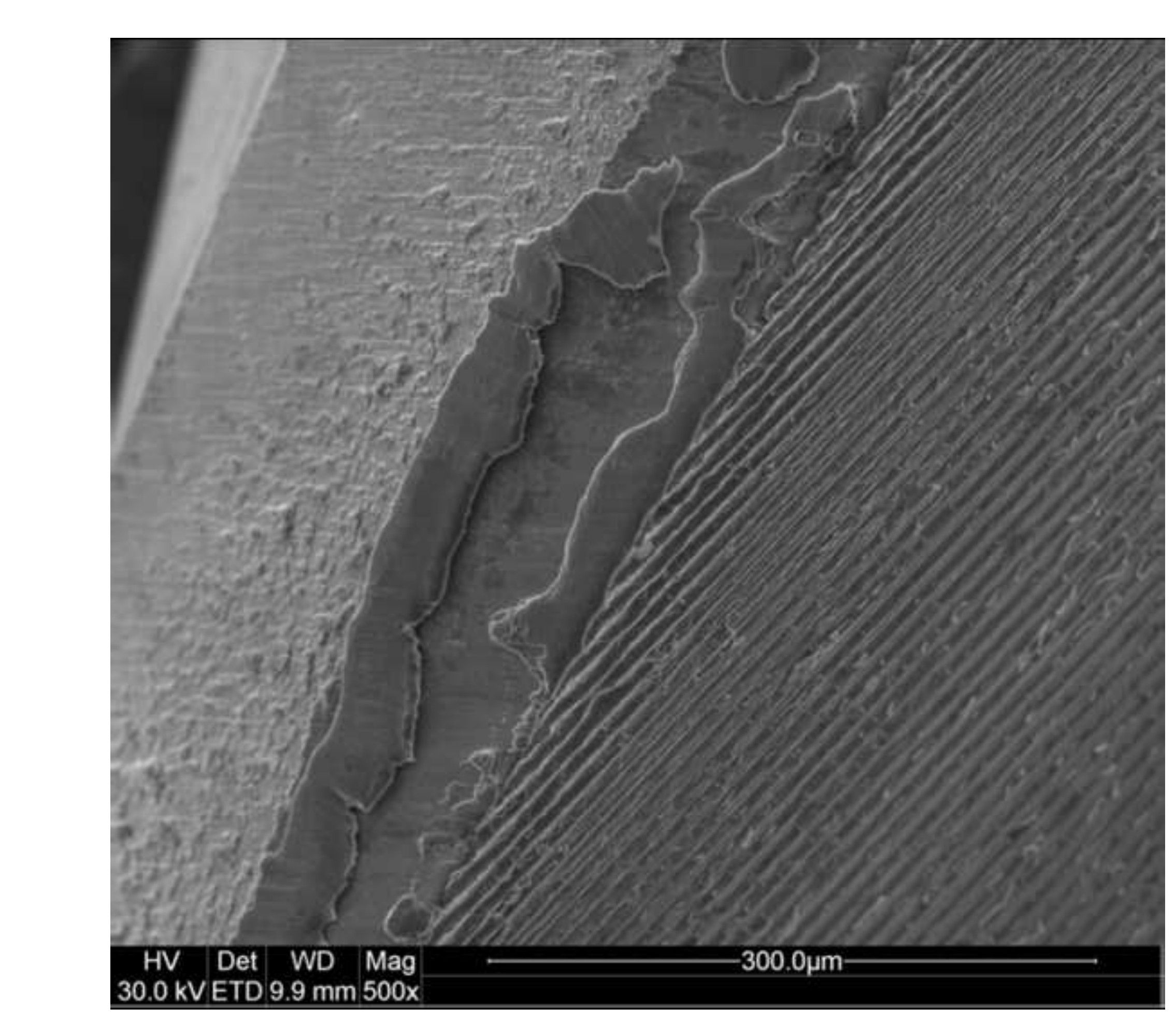

HV Det WD Mag
30.0 kVETD $9.9 \mathrm{~mm} 500 \mathrm{x}$ 
Fig. 13(b). Detail of UC endmill margin after $6.9 \mathrm{~m}$ cut length.

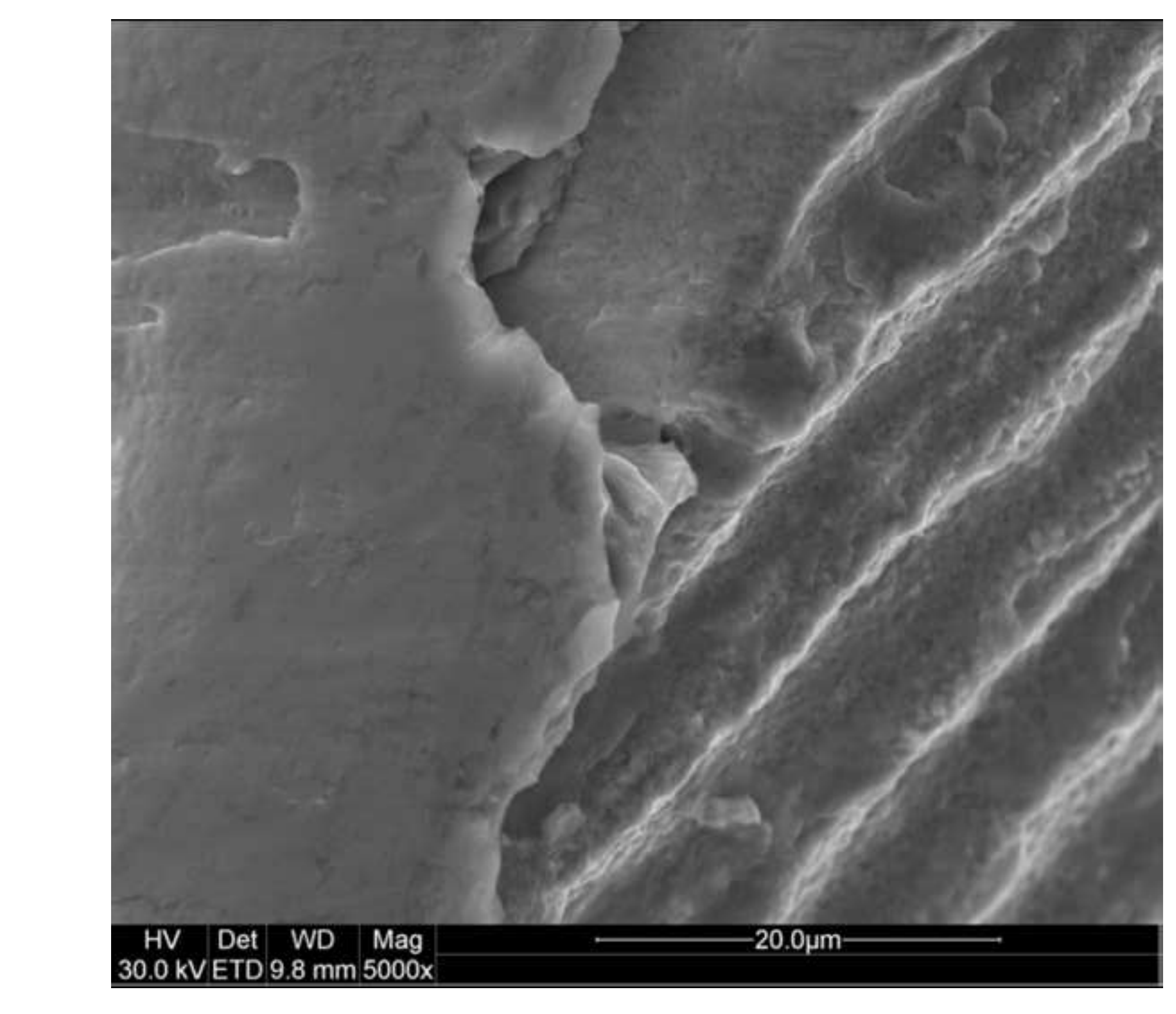

30.0 kV ETD $9.8 \mathrm{~mm} 5000 \mathrm{x}$

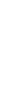


Fig. $13(\mathrm{c})$. AICrN coated tool margin after $31.5 \mathrm{~m}$ cut length.

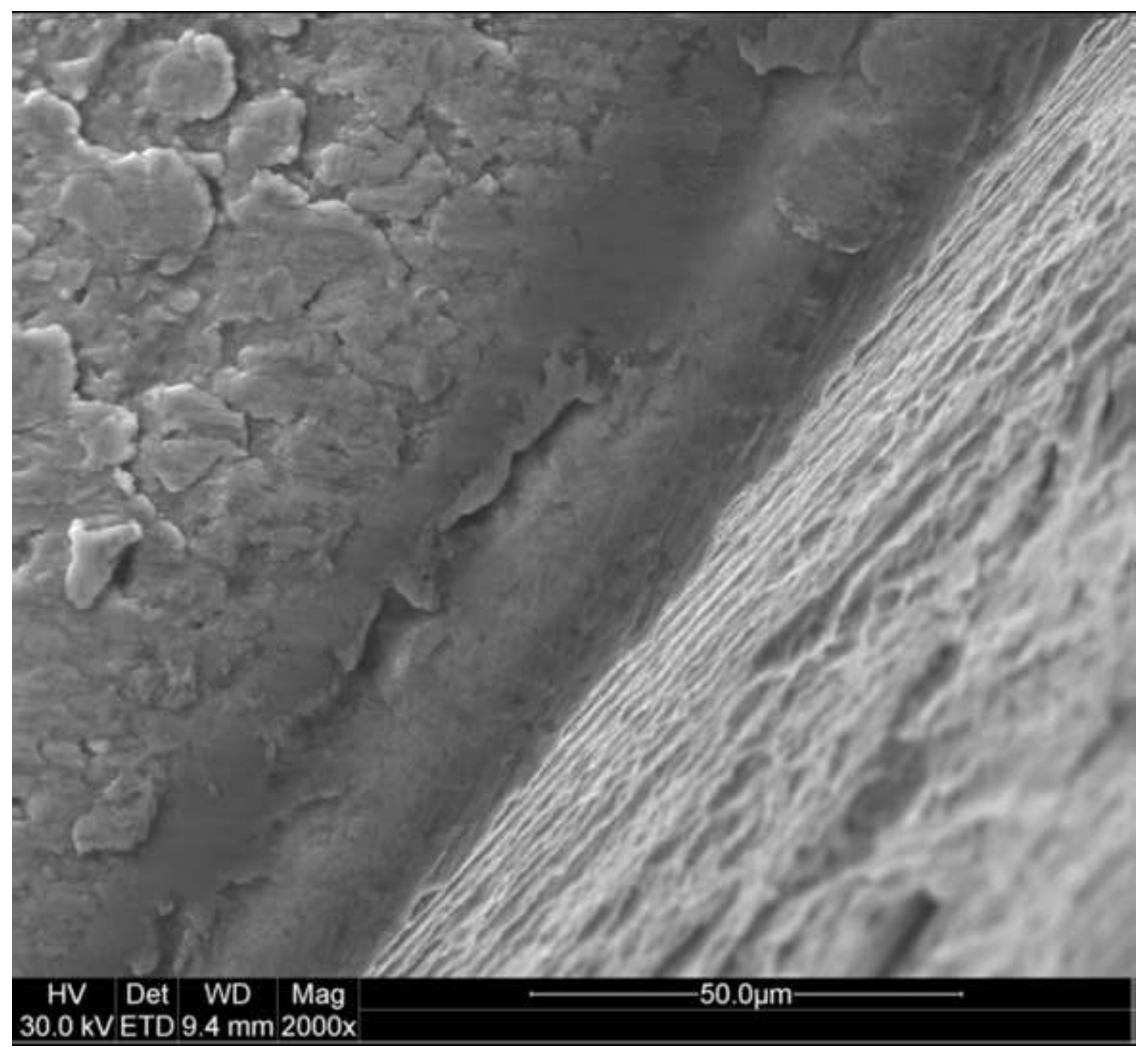


Table 1. Coating deposition parameters and layer thickness from tool lands.

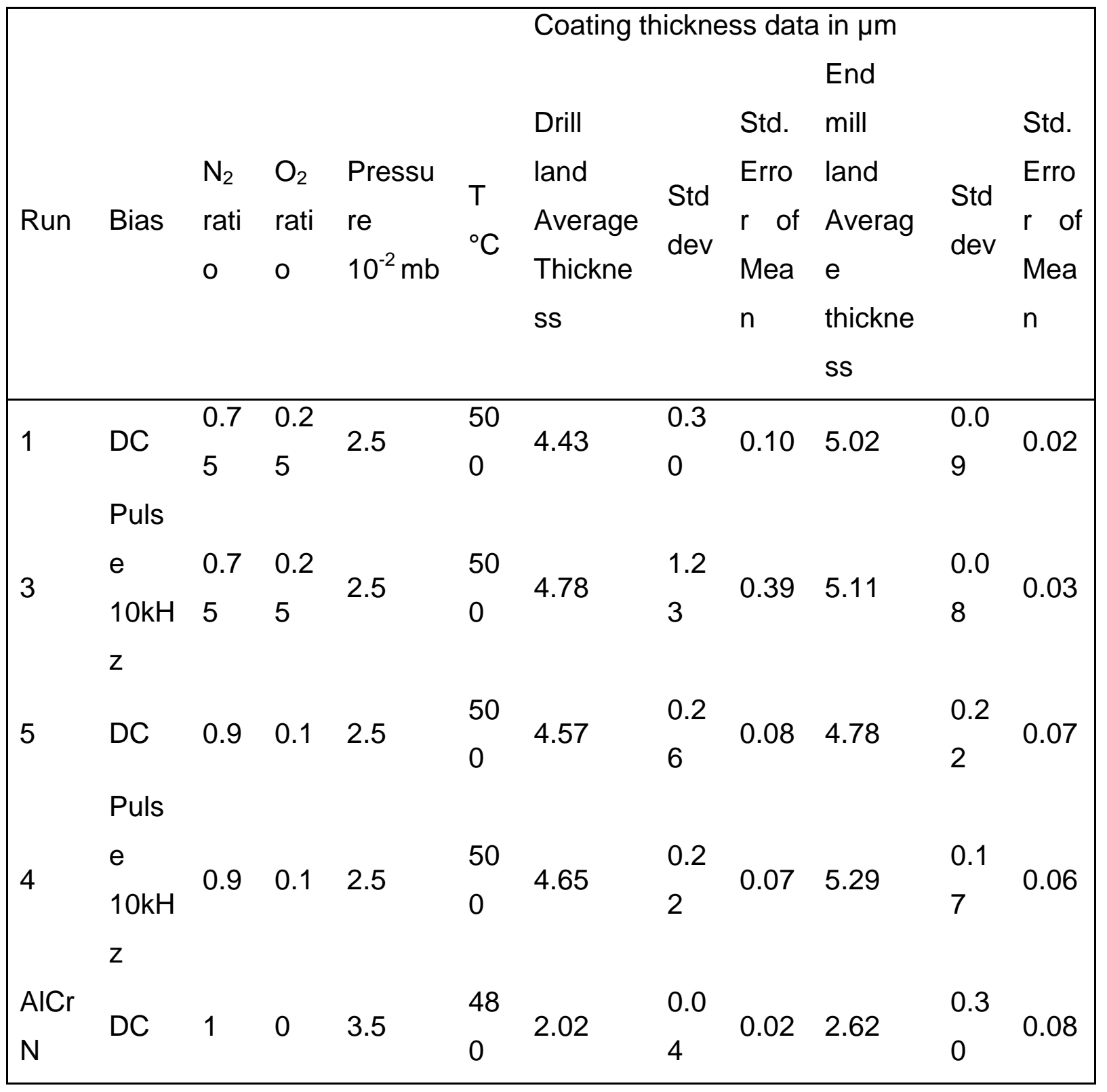


Table 2. Nanoindentation hardness and modulus of coatings.

Table 2. Nanoindentation hardness and reduced modulus of PVD coated WC coupons.

\begin{tabular}{|c|c|c|c|c|c|c|c|c|c|}
\hline Run & $\begin{array}{c}\text { Bias /reactive } \\
\text { gas }\end{array}$ & $\begin{array}{c}\mathrm{H} \\
\mathrm{GPa}\end{array}$ & $\begin{array}{l}\mathrm{SD} \\
\mathrm{GPa}\end{array}$ & $\begin{array}{c}\mathrm{Cl} \\
\mathrm{GPa}\end{array}$ & $\begin{array}{l}\text { Modulus E' } \\
\text { GPa }\end{array}$ & $\begin{array}{l}\mathrm{SD} \\
\mathrm{GPa}\end{array}$ & $\begin{array}{c}\mathrm{Cl} \\
\mathrm{GPa}\end{array}$ & $\mathrm{H} / \mathrm{E}^{\prime}$ & $\begin{array}{c}\text { range } \\
+-\end{array}$ \\
\hline 1 & $\begin{array}{c}D C \\
0.75 \mathrm{~N}, 0.25 \mathrm{O}\end{array}$ & 24.57 & 2.77 & 0.853 & 262.50 & 17.21 & 5.296 & 0.094 & 0.005 \\
\hline 3 & $\begin{array}{c}10 \mathrm{kHz} \\
0.75 \mathrm{~N}_{2} 0.25 \mathrm{O}_{2}\end{array}$ & 24.80 & 4.75 & 1.411 & 285.78 & 39.84 & 11.831 & 0.087 & 0.009 \\
\hline 5 & $\begin{array}{c}\mathrm{DC} \\
0.9 \mathrm{~N}_{2} 0.1 \mathrm{O}_{2}\end{array}$ & 32.96 & 2.36 & 0.685 & 337.29 & 12.51 & 3.633 & 0.098 & 0.003 \\
\hline 4 & $\begin{array}{c}10 \mathrm{kHz} \\
0.9 \mathrm{~N}_{2} 0.1 \mathrm{O}_{2}\end{array}$ & 32.36 & 2.09 & 0.629 & 332.37 & 17.75 & 5.334 & 0.097 & 0.003 \\
\hline AlCrN & DC & 32.63 & 2.51 & 0.571 & 382.86 & 20.53 & 4.659 & 0.085 & 0.003 \\
\hline
\end{tabular}

